Florida International University FIU Digital Commons

\title{
Teachers' knowledge, awareness, and pedagogy of global education in secondary schools
}

\author{
Abubakar Sadiq Abdullahi \\ Florida International University
}

DOI: $10.25148 /$ etd.FI13101508

Follow this and additional works at: https://digitalcommons.fiu.edu/etd

Part of the Education Commons

\section{Recommended Citation}

Abdullahi, Abubakar Sadiq, "Teachers' knowledge, awareness, and pedagogy of global education in secondary schools" (2004). FIU Electronic Theses and Dissertations. 1063.

https://digitalcommons.fiu.edu/etd/1063 


\section{FLORIDA INTERNATIONAL UNIVERSITY}

Miami, Florida

TEACHERS' KNOWLEDGE, AWARENESS, AND PEDAGOGY OF GLOBAL EDUCATION IN SECONDARY SCHOOLS

A dissertation submitted in partial fulfillment of the requirements for the degree of DOCTOR OF EDUCATION in

CURRICULUM AND INSTRUCTION

by

Abubakar Sadiq Abdullahi 
To: Dean Linda Blanton

College of Education

This dissertation, written by Abubakar Sadiq Abdullahi and entitled Teachers' Knowledge, Awareness, and Pedagogy of Global Education in Secondary Schools, having been approved in respect to style and intellectual content, is referred to you for judgment.

We have read this dissertation and recommend that it be approved.

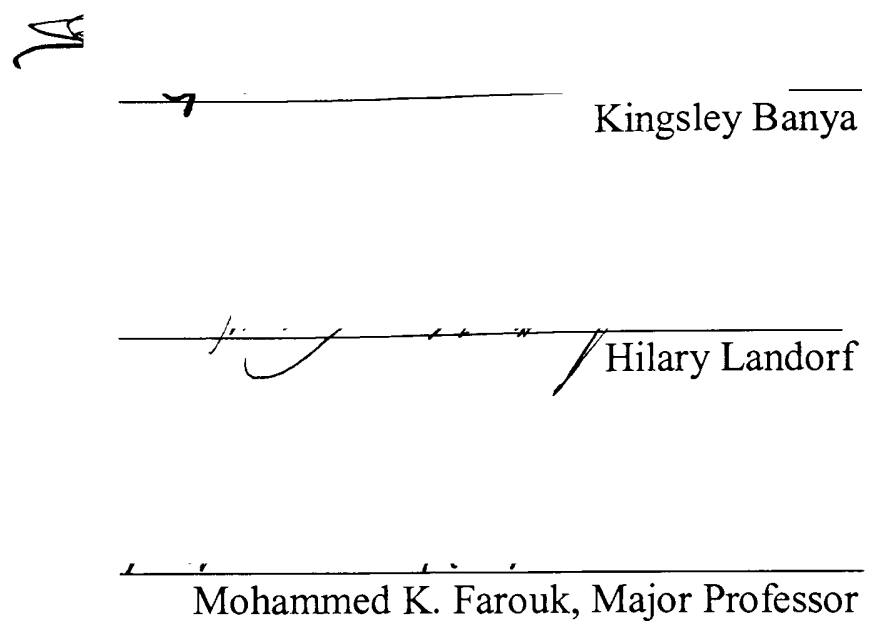

Date of Defense: July 20, 2004

The dissertation of Abubakar Sadiq Abdullahi is approved.
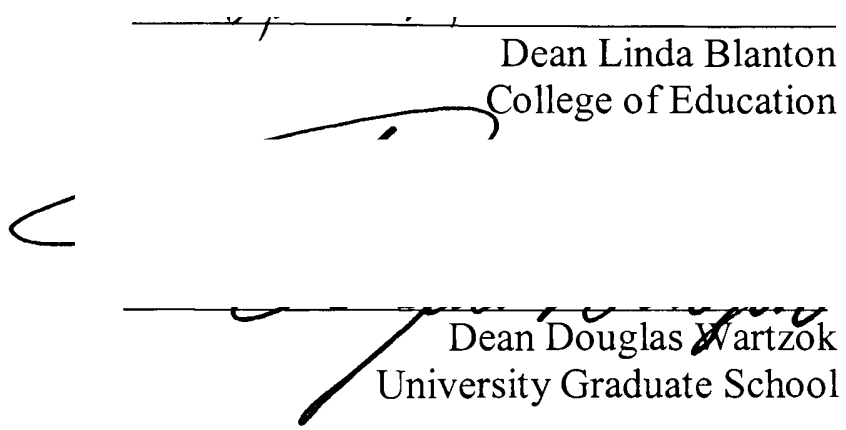

Florida International University, 2004 
(C) Copyright 2004 by Abubakar Sadiq Abdullahi

All rights reserved. 


\section{DEDICATION}

This dissertation is dedicated to my wife Claudine and my children Rasheeda, Monique, Fatimah, and Sadiq, Jr., and my mother and father for their unconditional love and support. In addition, this dissertation is dedicated to Ambassador Hamza and Amina Ahmadu, for their part in my primary and secondary education, especially their effort in sending me to Kufena College, Wusasa, Zaria, in Kaduna State, Nigeria, where I discovered myself and my purpose in life, and to the tennis legend, Arthur Ashe and Charlayne Hunter-Gault, for inspiring and encouraging me to further my education. 


\section{ACKNOWLEDGMENTS}

Thanks to Maria Dolores Rotolante, Leanne Wells, Tarek Chebbi, Serge Martin, Merilyn and Mark Himmels, Donna and Desmon Alufohai, Dr. Oyaziwo Aluede, Dr. Erskine Dotine, Dr. Jan Tucker, and Dr. Frank Di Vesta for providing support and encouragement.

Special thanks to my dissertation committee members, Dr. Hilary Landorf, Dr. Kingsley Banya, and my major professor, Dr. Mohammed Kabiru Farouk for their valuable advice, feedback, and mentoring. 
ABSTRACT OF THE DISSERTATION

TEACHERS' KNOWLEDGE, AWARENESS, AND PEDAGOGY OF GLOBAL EDUCATION IN SECONDARY SCHOOLS

by

Abubakar Sadiq Abdullahi

Florida International University, 2004

Miami, Florida

Professor Mohammed K. Farouk, Major Professor

In 1979, the Florida State Board of Education approved the teaching of global education in the state of Florida. The purpose of this study was to examine the factors that contributed to teachers' global knowledge, global mindedness, and pedagogy in global education. The Hanvey model of teaching from a global perspective was the theoretical framework for the study.

A total of 90 secondary teachers from Miami-Dade County Public Schools were randomly selected and placed in three groups: Globally Oriented Social Studies Program (GOSSE), Non-Globally Oriented Social Studies Program (non-GOSSE), and Teachers Who Teach Other Subjects (TWTOS). Seven teachers, two of whom team-taught a class, were selected for classroom observations and interviews. A mixed methods design that combined quantitative and qualitative data was used. ANOVA and Chi square techniques were used to determine whether the factors that contributed to teachers' global knowledge and global mindedness differ among groups. Classroom observations and interviews were conducted to determine whether the instructional strategies differ among the seven selected teachers. 
The findings of the study show that teachers who were trained in teaching from a global perspective differed in their global knowledge and used more appropriate instructional strategies than teachers who were not trained in teaching global perspectives. There was no significant difference in the combined global knowledge of the non-GOSSE and TWTOS groups when compared with the GOSSE group. There was no significant difference in the combined global knowledge of the GOSSE and nonGOSSE groups when compared with the TWTOS group. There was no significant difference among the teachers in their global mindedness. Observation and interview data indicate that current events, role-playing, simulations, open-ended discussion, debates, and projects were the predominant instructional strategies used by globally trained teachers. Cable networks, Internet, magazines, and newspapers were found to be the dominant tools for teaching global education.

This study concluded that teachers who were trained in globally oriented programs had more global knowledge than teachers who were not. It is recommended that teacher education programs should incorporate a global perspective in the preparation of social studies teachers, with particular attention to developing their global attitudes. 


\section{TABLE OF CONTENTS}

CHAPTER

PAGE

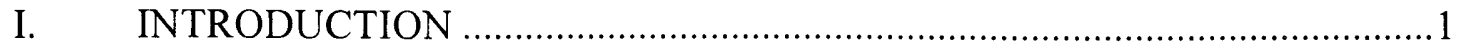

Statement of the Problem ...............................................................................

Purpose of the Study ............................................................................. 7

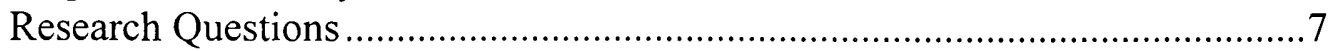

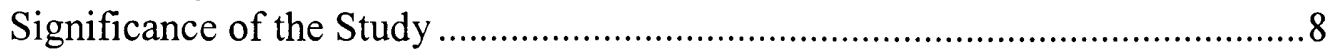

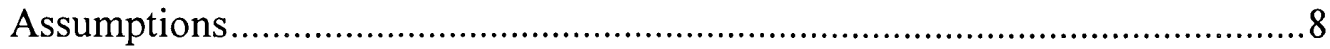

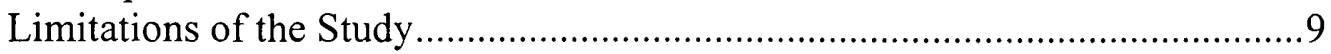

Definitions of Terms

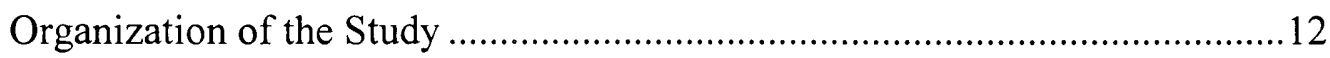

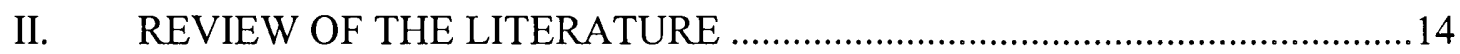

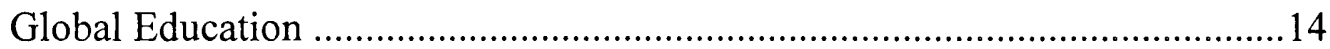

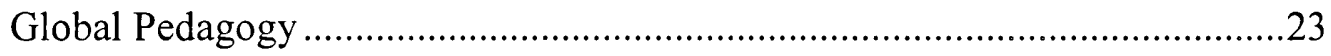

Conceptual Framework for the Study .....................................................29

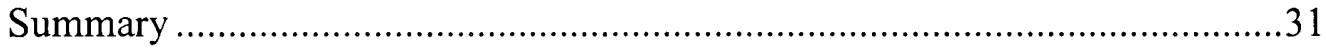

III. METHODS …

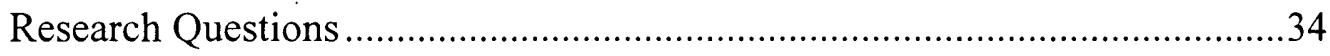

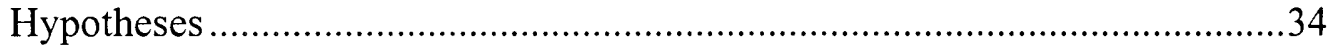

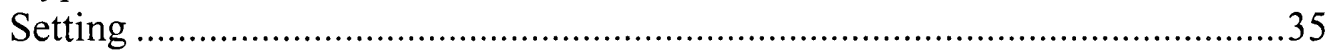

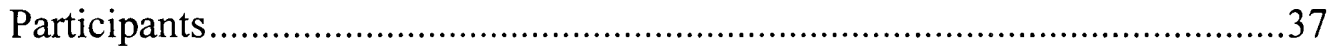

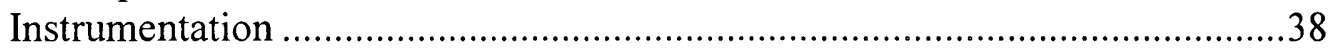

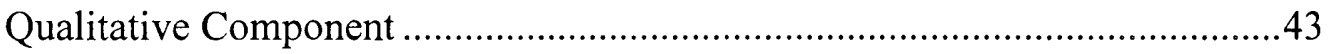

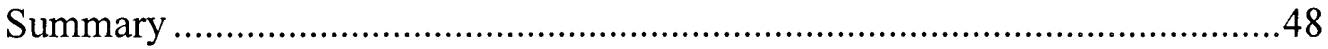

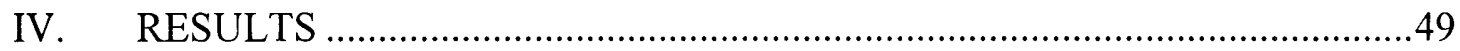

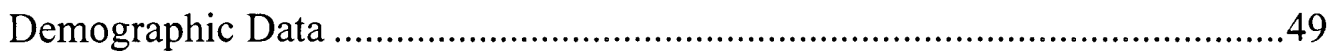

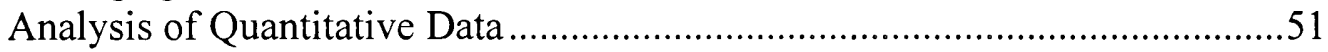

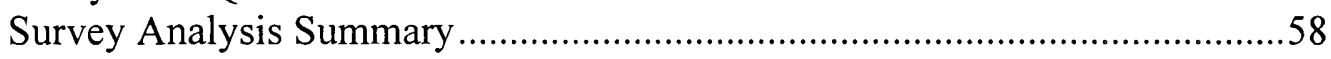

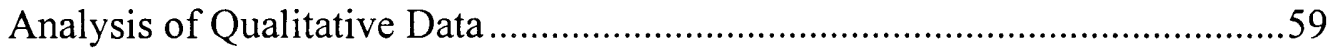

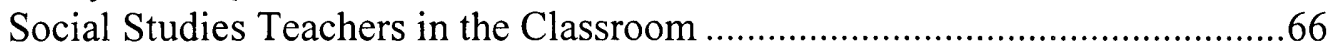

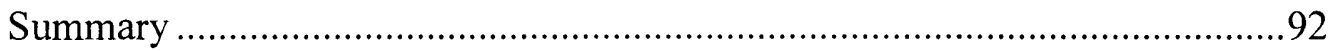

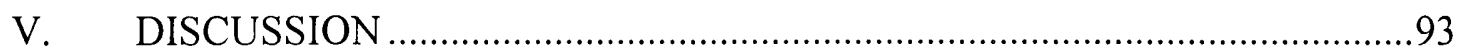

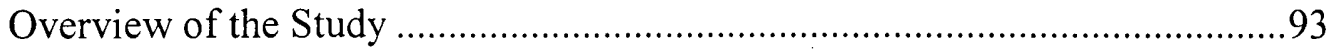

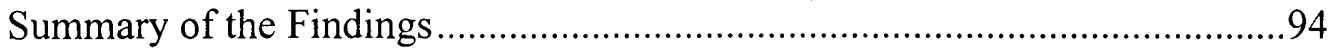

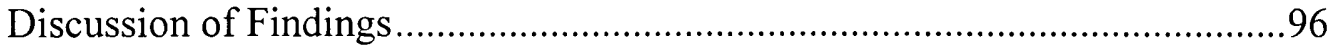

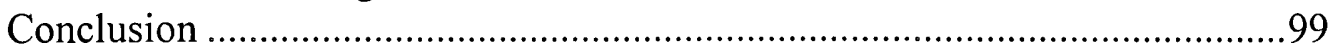

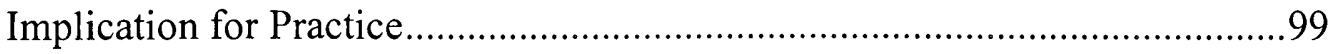

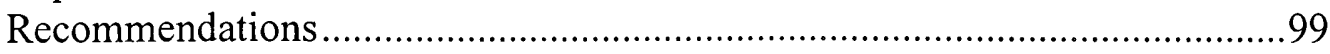

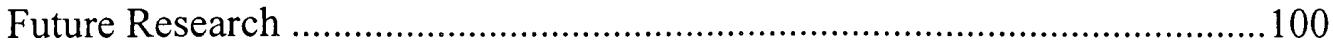




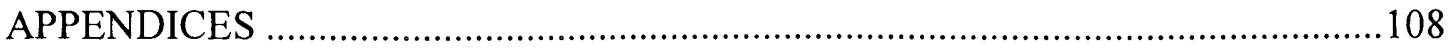

VITA 


\section{LIST OF TABLES}

TABLE

PAGE

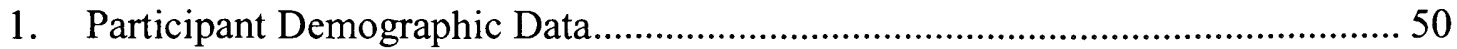

2. Summary Table of Means and Standard Deviation of

Global Thinking by Group Membership 52

3. Summary of Means of Raw Scores for Three Groups on

Global Knowledge

4. Summary of Means of Raw Scores for Three Groups on

Global Mindedness

5. Summary of ANOVA Showing Interaction of Global Thinking and GOSSE/non-GOSSE and TWTOS

6. Summary Table of a Mixed ANOVA of Global Thinking Scores 57

7. Summary of ANOVA Showing the Interaction of Global Thinking and GOSSE and Non-GOSSE and TWTOS. 58

8. Profile of Social Studies Teachers Selected for Classroom Observation 64

9. Similarities and Differences of Modes of Instruction and Teaching Strategies.... 90 


\section{CHAPTER I}

\section{INTRODUCTION}

The world we live in today is faced with difficult economic, cultural, technological, environmental and political problems. Political leaders and educators are continually faced with local, national, regional, and global challenges. The September 11, 2001 attack on America has forced political leaders around the world to adjust their foreign policy objectives in order to address national security threats posed by religious extremists or fundamentalists. Political and economic instability have led to many conflicts around the world. As a result, many people in the affected countries have migrated to or have sought refuge in neighboring countries, adding pressure to social infrastructure there. Environmental pollution and global warming also continue to pose serious threats to life on the planet. The global education curriculum is designed to address issues and problems such as those connected to human rights, global terrorism, regional conflicts, global warming, globalization, population growth, and acquired immunodeficiency syndrome (A1DS).

In 1968, the Foreign Policy Association issued a report: An Examination of Objectives and Priorities in International Education in U. S. Secondary and Elementary Schools (Becker, 1968). The report argued that changes in the world would require changes in the curriculum. In the early 1970s, global educators such as Lee Anderson, John Goodlad, Robert Hanvey, Jan Tucker, Kenneth Tye, Steven Lamy, Merry Merryfield, Toni Kirkwood, and James Becker responded and began a movement to globalize American education. They reasoned that a globalized American K-12 education would expand teachers' and students' global knowledge and global mindedness 
(Anderson, 1991; Kirkwood, 1995; Merryfield, 2001). In the late 1980s, a task force of U.S. Governors, spearheaded by then Governor of Arkansas, former president William J. Clinton, discussed the challenges and the importance of international education in American schools. The Task Force concluded that international education is as important as economic prosperity, national security, and world stability. Consequently, the Task Force issued a report in which it argued that it is time for governors to take the lead in creating an international focus for the U.S. educational system.

The Governors Task Force on International Education made seven specific recommendations: (a) international education must become part of the basic education of all of our students; (b) more of our students must gain proficiency in foreign languages; (c) teachers must know more about international issues; (d) schools and teachers need to know about the wealth of resources and materials, other than textbooks, that are available for international education; (e) all graduates of our colleges and universities must be knowledgeable about the broader world and conversant in another language; (f) business and community support of international education should be increased; (g) the business community must have access to international education, particularly information about exports, trade regulations and overseas cultures (America in Transition, 1989). Boyer (1984) of the Carnegie Foundation urged educators to develop curricular and teaching strategies that would recognize global interdependence and human interconnectedness. Similarly, national organizations such as the National Council for the Accreditation of Teacher Education (NCATE), the American Association of Colleges for Teacher Education (AACTE) and the National Council for the Social Studies (NCSS), as well as state departments of education supported and endorsed the teaching of global 
perspectives in American elementary and secondary schools. Wisconsin was one of the first state departments of education to promote international education. Other state departments beginning with those in Michigan, Ohio, New York, and Florida followed suit. National and state agencies were formed to design curriculum frameworks for global education. For example, in 1979, the Florida State Board of Education approved the teaching of global education in schools in Florida (Florida Department of Education, 1981). This allowed the Miami-Dade County School District to take steps to promote the infusion of global perspectives in county schools.

Based on the 1968 report, teacher education programs began to infuse global perspectives as well. Since the publication of the 1968 Foreign Policy Association report, teacher educators have developed various programs that have focused on expanding teachers' global knowledge and global mindedness through undergraduate courses, preservice and inservice programs, and organized foreign travel (Anderson, 1991). Furthermore, teacher educators developed other programs geared toward improving teachers' global thinking by developing global awareness programs through expanding the social studies curriculum with more content on Africa, Asia, Latin America, and the Middle East and through infusing the voices of others (Benitez, 2001; Cruz, 1990; Kirkwood, 1995; Merryfield, 2001, 1997; Zong, 1999).

Some secondary social studies teachers responded to this new emphasis in their preservice training by including U.S. foreign policy in their curricula, emphasizing the United States' involvement in the world (Merryfield, 2001). Some included in their curricula non-state actors such as individuals, multinational corporations (MNCs), and 
non-governmental organizations (NGOs) to show how these agencies were interacting globally and changing the world.

As Anderson (1991) has explained, some secondary global educators focused primarily on improving education about problems such as the maintenance of national security, the control of warfare, the reduction of world poverty, the promotion of human rights, and the preservation of ecological well being. Merryfield (2001) has pointed out that at the collegiate level instructors also began to teach preservice teachers to understand issues and problems through: (a) increasing their knowledge of local and global connections; (b) developing a global perspective consciousness; (c) increasing their cross-cultural awareness; (d) becoming more knowledgeable about global history and economic, political, ecological, and technological systems and institutions.

In 1991, the Association for Supervision and Curriculum Development (ASCD) devoted the yearbook to promoting global education by publishing the landmark Global Education: From Thought to Action (Tye, 1991). The authors, Lee Anderson, Barbara Tye, Steven Lamy, James Baker, Jane Boston, Ida Ura, Jan Tucker, Charlotte Anderson, Toni Kirkwood, and Kenneth Tye, explored the history, problems, and challenges facing global education in America. The yearbook attempted to accomplish three purposes: (a) to explain what global education is and why it is important in our schools, (b) to assist those who wish to develop their own global education program and (c) to offer recommendations for school improvement.

As an example of pioneering research in teacher education programs, in 1988 Merry Merryfield carried out a study to identify teacher education programs in America that prepared secondary social studies teachers to teach from a global perspective. She 
found that 88 programs prepared secondary teachers to teach from a global perspective. Thirty-two of the programs were profiled in Merryfield's 1992 Teaching About the World: Teacher Education Programs with a Global Perspective. Out of the 32 programs, six were found to be exemplary. The social studies and global education program at Florida International University (FIU) was one of those six exemplary programs. Others were: (a) the global education program at California State University at Long Beach; (b) Global REACH in Arlington, Virginia; (c) the Massachusetts Global Education Program in Winchester; (d) the Social Studies Program at the University of Kentucky; and (e) the social studies and global education program at Ohio State University (Merryfield, 1992).

\section{Statement of the Problem}

Global warming, environmental pollution, population growth, hunger, refugees, poverty, conflicts, inflation, diseases, the lack of widespread understanding of how democracy works, greed and corruption, intolerance, religious extremism, and the proliferation of nuclear weapons are connected to some of the major global problems whose solutions require considerable collective human efforts. Yet numerous studies have presented evidence that teachers at the secondary school level do not understand fully how these events, issues, and problems are interconnected and how global systems and institutions are interdependent (i.e., American Forum for Global education, 2002; Anderson, 1991; Kirkwood, 1995; Merryfield, 1997). Many studies in global education and international studies have also found that American teachers and students alike are apathetic about, as well as ignorant of, past and present global issues, problems and events (Goodlad, 1984; Kirkwood, 1995; Merryfield, 1992; Tucker, 1983; Tye \& Tye, 1991). 
In secondary schools, social studies teachers have the primary responsibility of raising awareness of global issues, problems, and events in the classroom. Therefore, for social studies educators the challenge lies in helping these teachers help their students improve their global knowledge and global mindedness (i.e., global thinking).

The researcher of this study is among those who are very concerned about this situation because for them there is a growing awareness that the world has not only become a small interdependent and interconnected village, but also a stage for increasingly hostile and violent situations caused by political and economic mismanagement. The consequences of this hostility and violence have become a core concern at all interconnected societal and educational levels. Global educators understand that teachers and students must become more responsive to these global issues and problems. Therefore, because of their position within secondary schools, social studies teachers must have the global knowledge, global mindedness, and pedagogical training needed to help students to understand how these phenomena can devastate humanity. To help address these $21^{\text {st }}$ century concerns, before they leave secondary school students must develop negotiation skills, critical and reflective thinking, and analytical skills to address emerging global, social, economic, environmental and political problems (Kirkwood, 2001; Merryfield, 2001). In the wake of the September 11, 2001 attacks, the U.S. Secretary of State, Colin Powell said that Americans must be engaged now more than ever before with the rest of the world. Three years after the attacks in New York and Washington, D.C., it has become increasingly urgent to promote global or international education in American schools. Finding out more about the factors that affect social studies teachers' use of global education can help make that 
promotion more effective. Factors identified in the literature and from the researcher's experience include pre- and in-service training, teacher gender, and length of time a teacher has been teaching.

\section{Purpose of the Study}

The purpose of this study was to examine the factors that contribute to teachers' global knowledge, global mindedness, and pedagogy concerning global education.

\section{Research Questions}

The following research questions are addressed in this study.

1. Is there a significant difference among teachers trained in Globally Oriented Social Studies Education (GOSSE), trained in non-Globally Oriented Social Studies education (non-GOSSE), and Teachers Who Teach Other Subjects (TWTOS) groups in their global knowledge and global mindedness?

2. Is there a significant difference between teachers in the GOSSE group and the non-GOSSE/TWTOS group in their global knowledge and global mindedness?

3. Is there a significant difference between teachers in GOSSE/non-GOOSE and TWTOS groups in their global knowledge and global mindedness?

4. Is there a relationship between age, gender, and years of teaching experience in teachers' global knowledge and global mindedness?

5. Do teachers from the GOSSE group teach from a global perspective and infuse global perspectives into the curriculum differently than teachers from the non-GOSSE group? 


\section{Significance of the Study}

This study is significant because it will provide empirical evidence to support efforts to promote the teaching of global perspectives in American secondary schools. Research continues to show that global and cultural knowledge contribute significantly to students' overall growth and development (Kirkwood, 1995). This study will help education policy makers at the local and state levels promote global education.

Miami-Dade County Public Schools (M-DCPS) is the fourth largest school district in the nation and employs approximately 800 secondary social studies teachers who teach students from different countries and cultural backgrounds. This study will help those and other teachers become more aware of a range of appropriate instructional strategies for teaching from a global perspective. The study also has implications for enhancing local social studies teacher education programs by providing information and ideas for improving teachers' global knowledge, global mindedness, and classroom practice in the M-DCPS. Additionally, the study will contribute to educators' understanding of the factors that may affect teachers' global thinking and classroom practices.

\section{Assumptions}

The basic assumptions of this study are:

1. Global education and globalization are interrelated and interdisciplinary concepts.

2. Teachers' responses to the survey instruments used in this study reflect their authentic global knowledge, understanding, and awareness. Authentic in this study refers to teachers' true knowledge and understanding of the world. 
3. Understanding global education and globalization and their linkages will make a difference in the development of teachers' global pedagogical strategies and attitudes.

4. Global education and globalization processes impact many sectors in society especially those involving politics, the environment, the economy, technology, culture, and education.

5. Global education has a moral purpose (Kirkwood, 2001).

6. Social studies teachers should use a conceptual framework or model to teach from a global perspective.

7. The extent to which a social studies teacher teaches from a global perspective is influenced by the kind of training he or she received.

\section{Limitations of the Study}

Only high school teachers participated in the study. Therefore, caution should be taken concerning generalizing study findings from them to elementary and middle school teachers in M-DCPS. Another limitation was the small number of classroom observations. Only seven social studies teachers were observed. The viewpoints of these teachers cannot be said to totally represent the views of all social studies teachers in the school district. Another limitation was the inherently subjective nature of the classroom observation interpretations.

\section{Definitions of Terms}

For the purpose of this study, the following terms convey the meanings as set out below. Other terms will be explained as they are introduced. 
Awareness of human choices. With more knowledge people tend to better understand their interconnectedness with other individuals, nations and the human species throughout the global system.

Cross-cultural awareness. An awareness of the diversity of ideas and practices to be found in societies around the world, how such ideas and practices compare; including some limited recognition of how the ideas and ways of one's own society might be viewed from other vantage points (Hanvey, 1976).

Global citizenship. An idea or concept that transcends national identity and national political boundaries, recognizes choices impact all directly or indirectly, and realizes that the peoples of the world share more commonalities and similarities than differences.

Global co-operation. The mutual collaboration of ideas, efforts, initiatives, technologies, information, transportation, labor, finances, and economics around the world.

Global education. A worldwide education movement that involves the teaching and learning of problems and issues that go beyond national boundaries.

Global knowledge. A composite or set of scores from a standardized instrument that reflects the knowledge of various features of the world and how it works; knowledge of interconnected global systems, international events, world cultures, and world geography.

Global mindedness. A worldview in which one sees oneself as connected to the world community and feels a sense of responsibility to its members. It includes the 
following five dimensions: responsibility, cultural pluralism, efficacy, global centrism and interconnectedness.

Global perspective. The viewpoint that accepts the interdependence of nations and peoples and the inter-linkages of political, economic, ecological, and social issues of a transnational and global character; a loose assemblage of modes of thoughts, sensitivities and intellectual skills (Case, 1993). It consists of global knowledge, attitudes, and awareness, and when put together, helps students understand not only the make-up, but also the intricacies and complexities of the world.

Global security. The freedoms, rights, privileges, amenities, and luxuries extended to and enjoyed by global citizens everywhere in the world.

Global thinking. The ability to process and evaluate global information.

Globalization. Globalization is the integration of technological, informational, economic, cultural, and political forces operating and interweaving within the global markets.

Globally-oriented social studies education program (GOSSE). Teachers in this program took a core course in teacher education with a focus on preparing teachers to teach with a global perspective.

Interconnectedness and interdependence. The interrelated and mutual connectedness of systems, cultures, environments, politics, and technologies.

Knowledge of global dynamics. The comprehension of key traits and mechanisms of the world system, with emphasis on theories and concepts that may increase intelligent consciousness of global change (Hanvey, 1976). 
Non-globally oriented social studies education. Refers to programs that participating teachers indicated did not include a course in teaching from a global perspective.

Teachers who teach other subjects. This group refers to secondary teachers who do not teach social studies subjects.

Pedagogy for global instruction. The practice of teaching global content in ways that provide students with the opportunity to acquire knowledge about the world, problem solving skills, and the disposition to use them.

Perspective consciousness. The recognition or awareness on the part of the individual that he or she has a view of the world that is not universally shared, that this view of the world has been and continues to be shaped by influences that often escape conscious detection, and that others have views of the world that are profoundly different from one's own (Hanvey, 1976).

State of the planet awareness. An awareness of the prevailing world conditions and developments, including emergent conditions and trends such as those related to population growth, migration, economic conditions, resources and physical environment, political developments, science and technology, law, health and inter-nation and intranation conflicts (Hanvey, 1976).

\section{Organization of the Study}

Chapter I presents an overview of this research project. It provides an introduction, statement of the problem, purpose of the study, research questions, significance of the study, assumptions, limitations of the study, and definition of terms. 
Chapter 2 presents a review of related literature on global education and globalization, including the theoretical orientations, empirical findings relevant to the problem, and the conceptual framework of the study.

Chapter 3 provides the research design and methods used in the study. The setting and participants are described. Methods of data collection and analysis are described and explained.

Chapter 4 presents the results of the study in two sections, quantitative and qualitative. The chapter provides analyses of the data collected. Comparisons are made among groups and selected teachers. Findings from the classroom observations and interviews are examined to determine how global knowledge and global mindedness contributed to teachers' choice and application of instructional strategies in their classrooms.

Chapter 5 presents conclusions drawn from the research findings, and offers recommendations for further research and practice. 


\section{CHAPTER II}

\section{REVIEW OF THE LITERATURE}

This chapter provides a review of the literature on global education and global pedagogy. The chapter is organized into the following subsections: the nature of global education, global pedagogy, and the conceptual framework of the study.

\section{Global Education}

Anderson (1991) has offered a broad definition of global education:

Global educators at the pre-collegiate level have focused on expanding and improving the study of world history, world geography, world economics, world politics, or world ecology. Others seek to expand students' understanding of cultural diversity through the cross-cultural study of literature, art, music, dance, religion, and social customs. Many seek to expand and improve the study of foreign languages, including the rarely studied languages that are of growing importance to the United States, such as Japanese, Chinese, Russian, and Arabic.

Many global educators devote their energies to improving instruction about the often-slighted regions of the world: Asia, Africa, the Middle East, and Latin America. Still others focus on improving education about world problems such as the maintenance of national security, the control of warfare, the reduction of world poverty, the promotion of human rights, and the preservation of ecological well-being. Some seek to place the study of American society and its history in a world context so as to highlight the ways in which American cities, states, and the nation as a whole are linked to the rest of world. (p.13)

The need to enhance a student's knowledge of the world through global education is greater now than at any previous time (Benitez, 1994; Case, 1993; Cruz, 1990;

Kirkwood, 2001; Tucker, 1983; Zong, 1999). The teaching and promotion of global education is presently mandated by the National Council for the Accreditation of Teacher Education (NCATE, 1995) and is supported by the National Council for the Social Studies (NCSS, 1982). 


\section{Background}

Anderson (1991) has provided three strong reasons for global education. First, in the past two decades three basic historical changes in the social structure of the world have converged: the acceleration of growth of global interdependence, the erosion of western dominance, and the decline of American hegemony. He noted that the growth of interdependence could be observed in the expansion of technological, political, cultural, economic, and ecological institutions and networks connecting different peoples, cultures, civilizations and regions.

Furthermore, he argued that since the 1970s, western dominance has eroded in several ways. He observed that the decolonization efforts in some regions of the world after World War II, the cultural renaissance and self-assertion of old civilizations and cultures, and the emergence of the Organization of Petroleum Exporting Countries (OPEC) in the 1970s, have seriously undermined American hegemony and western domination. Second, because of this convergence of historical trends, American society in the 1970s, 1980s, and 1990s became more globalized and will likely become even more so in the $21^{\text {st }}$ century.

Anderson (1991) also pointed out that education mirrors society in the sense that social change generates educational change. As one example of this social context, in 1981 The Educational Testing Service (ETS) asserted that developing a global perspective improves students' cognitive and affective development. Their position was that a student's cognitive development involves providing him or her with the knowledge base necessary for an adequate understanding of global situations and processes. In that same year Becker (1981) suggested that the goals of global education include knowledge 
and appreciation of other cultures, an awareness of advancements and development in technology that are compressing time and space, an understanding of the interdependence of people and systems of the world, learning how to analyze global problems and working towards a peaceful resolution of global conflicts.

The following year the NCSS provided a rationale for developing a global perspective in schools:

The human experience is an increasingly globalized phenomenon in which people are constantly being influenced by transnational, cross-cultural, and multicultural interactions; there are a variety of actors (states, multinational corporations, private voluntary organizations, individuals etc.) on the world stage; the fate of humankind cannot be separated from the state of the world environment; there are linkages between present social, political, and ecological realities and alternative futures and citizen participation is critical both in local and world affairs. $(1982, \mathrm{p} .1)$

That same year, the NCSS issued 10 strands that form the framework of the current social studies curriculum standards. One of the strands focuses on developing and making global connections (NCSS, 1982). Furthermore, the organization recommended that the social studies K-12 program should have substantial instructional programs designed to develop global awareness and understanding of global connections.

Thirteen years later NCATE similarly recommended that colleges of teacher education offer programs that emphasize developing a global perspective. In response, social studies teacher education programs in accredited colleges restructured their academic programs to accommodate NCATE standards (NCATE, 1995). Some program leaders have incorporated themes and concepts such as population growth, political economy, global environment, conflict and cooperation, human rights, world economy and international terrorism in the curricula of their teacher training programs. 


\section{Developing a Global Perspective}

In 1987, the Commission on Global Education recommended that emphasis be placed in developing a better understanding of four curriculum areas: (a) the world as a series of interrelated systems: physical, biological, economic, political and informationalevaluative, (b) the development of civilizations as they relate to American history, (c) the diversity of cultural patterns both around the world and within the United States and (d) policy analysis of domestic and international issues (Study Commission on Global Education, 1987).

As global issues and events became more complex, the NCSS in the summer of 1994 issued another declaration calling on social studies teachers to include the experiences and cultures of peoples from around the world in their programs and units. The NCSS declared that students should be helped to construct a global perspective that includes knowledge, skills, and commitments needed to live wisely in a world that possesses limited resources and that is characterized by cultural diversity (NCSS, 1994). In the process, students will develop a sense of responsibility in themselves and the commitment to finding just and peaceful solutions to social and global problems.

Concerning a curriculum that would enhance students' global knowledge and their development of global perspectives, Lamy (1991) has written that the structuring of global education programs should include: (a) the introduction of participants to substantive and verifiable information that represents other interests, (b) courses or programs in global education that provide participants with opportunities to explore the core assumptions and values that define their worldviews, (c) the preparation of students for the future by exposing them to multiple perspectives and to a wide range of analytical 
and evaluative skills and (d) the introduction of students to strategies for participation and involvement in local, national and international affairs.

Also concerning global education curricular decisions, Case (1993) has argued that global perspectives should have a substantive and perceptual dimension. In the substantive dimension, he stressed that knowledge of various features of the world and how they work should be emphasized in order to improve student cognitive development. Teachers should promote knowledge of people and places beyond the student's own community and country, and knowledge of events and issues beyond the local and immediate environment. In the perceptual dimension, teachers should encourage students to use the substantive global knowledge as a lens with which to focus their discussion of controversial global issues. Concepts such as open-mindedness, open-ended discussion, global peace, justice, and citizenship should be fully integrated into classroom discussions.

Along similar lines Kirkwood (1995) has written that global education is designed to expand an individual's perception of the world. Students with a global perspective are sensitive to the multicultural, bilingual, multilingual and transnational nature of the human condition. She argues that students should exhibit an intellectual curiosity about the world that transcends local and national boundaries. Furthermore, Demovsky and Niemuth (2000) have posited that a global education curriculum should select content that establishes linkages between various interacting global systems. They argue that global content should reflect the fact that all global issues such as the environment, political economy, sustainable development, the world economy, and security are closely interrelated and interconnected. 
Various researchers have reasoned that students would develop multiple perspectives and global mindedness, as well as cross-cultural understanding and appreciation, if teachers were exposed to global problems, issues, and events and to training in the use of appropriate strategies (Case, 1993; Kirkwood, 1995; Massialas, 1999; Merryfield, 1997). In accordance with this stand, Merryfield (1997) has argued that global education curriculum should have the following elements: (a) human beliefs and values, (b) global systems, (c) global issues and problems, (d) global history, (e) cross-cultural understanding and interaction, (f) awareness of human choices, (g) development of analytical and evaluative skills and (h) strategies for participation and involvement.

At the turn of the new century global educators such as Merryfield (2001) have argued that the field of global education should be reconceptualized to reflect new global realities. She has suggested that emphasis should be placed on multiple perspectives and on other voices in the global educational discourse. She argued that the center of global education should include multiple voices, moving away from Euro-centric, imperial worldviews that divide the world toward a global-centric and cross-cultural worldview that unites the world. Moreover, Merryfield suggested that there is a need to reexamine what global knowledge teachers' have and how they teach in the classroom. The American Forum for Global Education (2002) echoes the importance of developing, promoting, and teaching global perspectives in schools around the world. Accordingly, Tonkin (2002) maintains that a global education curriculum will become significant when global issues, problems, and challenges become relevant to the lives of teachers and students. 
The American Forum for Global Education (2002) supports the structuring of global education curricula in American schools to include: conflicts, economic systems, global belief systems, human rights, planet management and empowerment, political systems, population, race and ethnicity, the technocratic revolution and sustainable development. This type of curriculum framework that is centered on issues, conflicts and systems should stimulate students' interest in exploring and debating global issues. It should also expand their scope and vision of responsibility and sensitivity as well as vision of global citizenship.

Some of the issues in globalization are explored in a global education classroom. For example, the uneven economic growth around the world is attributable, in part, to globalization. This global issue should be given adequate attention in the classroom. As Grossman (1998) argues, students are becoming incompetent citizens in a world characterized by globalization. Hayhoe and Pan (2001) suggested that emphasis should not only encompass economic, financial, and technological aspects, it must also focus on human, spiritual dimensions, and on the interdependence of humanity and its rich diversity within the context of cultural understanding. Foster (2002) agrees that the impact of globalization on education has necessitated a critical review of issues common to everyone in the context of learning about other cultures.

Stromquist and Monkman (2000) argue that globalization has been studied primarily as an economic and technological phenomenon, not from an educational or cultural perspective, and suggested that research should be conducted to change this trend. Research provides the data, analysis, and interpretations that help change people's 
perceptions. For example, as they read research, if educators think about what they have read, internalize it, and begin to see support for a particular instructional approach (such as global education), they might apply it in their own teaching. They argue that the emerging interest in globalization and education has brought up several new research topics: training, higher education, culture, the environment, industrialization strategies, information management, migration, labor, multinational affairs, and rural and agricultural development. Friedman (1999) believes that globalization has brought many positive changes such as a high standard of living, and capital development around the world. Barber (1995) notes that globalization in some ways is dividing the world. He observes that throughout the world traditional values and beliefs are continuously being challenged by modernization. Moreover, he argues that market capitalism, modern music, secularism, female emancipation, and new relationships between the sexes are eroding many traditional values in some cultures. Teachers can help students explore the complexities and contradictory perspectives that are embedded in these phenomena.

The researchers cited above have recognized the need for people around the world to have knowledge and understanding of global issues, problems, and events. Global education curricula will be enhanced if their different views or conceptualizations of the problems of the world are integrated into the social studies curriculum. What all the researchers have emphasized is fourfold: (a) the world is shrinking due to globalization, transportation, and technology, (b) globalization has positive and negative impact, (c) the negative impact is causing serious economic hardship to people around the world, especially people in the third world countries, and (d) global education will provide the knowledge base for understanding global issues and problem. Many global educators 
believe that global political and economic structural transformations have ushered in a need for a new way of thinking about the world and its people. The new knowledge requires that new strategies and methods be adapted if we want to educate students about emerging issues and problems of the world (M. Farouk, personal communication, April $15,2001)$.

\section{Global Education in Florida}

In 1993, The State of Florida first developed the Sunshine State Standards in an effort to improve and raise student academic achievement. The need for public schools to reform in order to meet the needs of diverse students in the new world was echoed in the Florida Curriculum Framework for Social Studies (1996). The document articulates state-mandated academic standards that raise expectations for student achievement. It also includes an overview of best practices in instruction for local educators to further investigate. This curriculum framework was developed to serve as a guideline for social studies instruction in the public schools.

According to the Florida Department of Education (1996), students must be ready to compete in a globalized world. In order to compete effectively, students must: (a) be prepared to make well-reasoned, thoughtful, and healthy lifelong decisions in an everchanging world. Students must learn how to locate, comprehend, interpret, evaluate, manage, and apply information from a variety of sources and media; (b) they must learn how to communicate effectively in a variety of settings and for a variety of purposes through many different media; (c) they must develop mathematical skills to analyze information, solve problems, and create products to meet new needs; (d) they must become creative and critical thinkers, skilled in systematic problem solving; (e) they must 
learn to wisely allocate time to solve problems; (f) they must learn to understand systems and to use technology and (h) they must develop the integrity to work cooperatively and effectively with people from many diverse backgrounds.

The general structure of global issues falls within the Florida Curriculum Framework and NCSS's goals and objectives. Florida's System of School Improvement and Accountability Commission's Goal 3, Standard 10 (1996), supports the vision, objectives and goals of global education. The Commission asserts that: Florida students should appreciate their own culture and the culture of others; understand the concerns and perspectives of members of other ethnic groups; reject the stereotyping of themselves and others; and seek out and utilize the views of persons from diverse ethnic, social, and educational backgrounds (Florida Department of Education, 1996).

\section{Global Pedagogy}

Many studies have been conducted to learn more about how teachers infuse and implement global education strategies in the classroom; whether they employ a global pedagogy (Benitez, 2001; Cruz, 1990; Kirkwood, 1995; Merryfield, 1998; Tucker, 1983; Zong; 1995). Global pedagogy is the practice of teaching and learning globally oriented content in ways that support the goals of global education (Merryfield, 1997). When teachers employ a global pedagogy, students' curiosity and interest in the problems and issues of the world will be enhanced. Students will also become aware of their own and other people's values. It is within this context that Becker (1990) suggests that effective teaching of global perspectives must be approached from the context of an integrated, interdisciplinary school curriculum. 


\section{Curricular Approaches}

Giroux (2002), a proponent of critical pedagogy in American public schools, believes that educators have an important role to play in encouraging a critical examination of American history, culture, and foreign policy. This critical pedagogy is essential for understanding global problems, issues, and events. The term critical pedagogy as used in this study refers to a method of instruction that prepares students to closely and critically examine political, social, economic, and environmental issues and problems, including structures and behavior of individuals in power and authority - with an eye toward reconstructing society.

Diaz, Massialas, and Xanthopoulos (1999) offer two approaches to teaching global perspectives: discrete and infusion. They believe that the discrete approach, which consists of (a) creation of a separate unit or separate course and (b) the infusion approach provide alternatives for global instruction. They argue that one of the disadvantages of creating a separate unit is that students may or may not make the connection to global knowledge and to the rest of the curriculum. In the infusion approach, a secondary social studies teacher in a given subject area integrates global content and information into his or her instruction, using current local, state, national, and international issues. They argue that issues in global education are better explored using the infusion approach. However, they also argue that the infusion approach may pose some difficulties for teachers, in the sense that some of them may not have the necessary global knowledge and information to apply to their teaching or when they have inadequate training in infusing global perspectives in the classroom. 
They believe that global education curriculum should include: (a) teachers' awareness of the attitudes toward global education that are present in the schools and communities where they teach; (b) teachers' awareness and use of (either exclusively or in an integrated manner) the following models as frameworks for organizing global knowledge - the Hanvey, Kniep, Merryfield, and White models; (c) an emphasis on heterogeneity, not homogeneity; (d) the pedagogical involvement of the cognitive, affective, and participatory domains; and (e) the discussion of some controversial issues. Many social studies teachers believe that critical issues might best be taught in a secondary classroom using the constructivist approach. This approach is based on the premise that students have the capacity to develop, create, and recreate their own knowledge, and focuses on students' cognitive development of their learning faculties (Gabler \& Schroeder, 2003; Sunal \& Haas, 2002). Sunal and Haas offer suggestions for organizing global knowledge within a constructivist paradigm. Concerning curriculum, they argue that global issues and problems could be divided into: (a) peace and security, (b) national and international development, (c) environmental problems and (d) human rights.

\section{Classroom Environment}

Grossman (1980) believes that there is a relationship between an open-ended environment and the discussion of controversial issues. But Benitez, (2001) points out that some classrooms still reflect the traditional model where students sit quietly in rows with little interaction or no discussion. They copy notes from the blackboard, listen to brief comments from the teacher, and complete worksheets and written assignments. 
Taylor (1998) believes that teachers will find non-traditional strategies such as simulation, role-playing, and comparative studies helpful to students in understanding global issues and problems.

Grossman (1998) has warned that one of the problems in global education is the failure to provide students with authentic learning experiences. Merryfield (2001) has observed that authentic learning must include the following elements: higher order thinking, depth of knowledge, substantive conversation, and connections to the world beyond the classroom. Banks (2003) believes that the transformative perspective will provide students with a better alternative in understanding global events, issues, and concepts than the Euro-centric perspective. He has written:

Students should also study world events, issues, and concepts from a transformative rather than a Eurocentric perspective. The world studies program in schools often uses a Eurocentric approach to examine problems, issues, and concepts. There are opportunities in the school curriculum to link global education helps students to view international events, concepts, and issues from the perspectives of the ethnic and racial groups that live in the various nations of the world. (p.22)

In order to help students develop a global perspective, social studies teachers should use instructional strategies adapted to teaching global concepts, issues and problem solving. Merryfield (1993) believes that effective global education teaching and learning require the recognition of the critical teaching moment. She has argued that reflection on global events is one way of improving classroom practice. Finally, Byrnes (1997) has identified three promising practices and tendencies in global education classrooms: emphasis on interdisciplinary concepts, model inquisitiveness and skepticism, and stress participatory learning. It is within this context that the pedagogy of issues-centered education becomes practical and meaningful. 


\section{Issues-Centered Global Education}

Issues-centered education is a dimension of global pedagogy. Tonkin (2002)

believes that issues-centered curriculum encourages students to argue controversial issues, and as they do that they will be expanding their sense of responsibility as global citizens. Benitez (2001) believes that the issues-centered strategy, if used at the higher level of Bloom's taxonomy, will cause students to critically analyze and evaluate global events and issues. Demovsky and Niemuth (2000) have suggested that a global education curriculum should select content that establishes global linkages between various disciplines and global systems. Gaudelli (1999) has suggested that teachers avoid controversial issues and self-criticism, if they are not familiar with issue or controversy under discussion. He argues that some teachers are slow to engage their students in controversial issues because they assume that their students have not attained global knowledge and are often immature. Diaz et al. (1999) have suggested that teachers expose their students to controversial issues in an open classroom setting. They argue that by doing so, students will develop citizenship skills and positive disposition towards global issues and events.

Merryfield and White (1996) believe that teachers typically do not approach issues-centered global education with clear objectives and a variety of strategies to infuse global content into the social studies curriculum. They believe that a global teacher must have a framework and suggested that (a) teachers build a foundation at the beginning of the unit, (b) link issues to social studies content, (c) plan authentic and personal experiences and (d) plan time for reflection. In building a framework, they stressed that teachers must develop perspective consciousness through examination of conflicting 
perspectives on historical or contemporary events as well as examining information across local, national, regional, and global data bases. They argue that having an issuescentered global education framework and strategies are critical for effective teaching of global education.

Longstreet (1996) believes that an issues-centered global education approach creates an intellectual hub that opens opportunities for students to become competent in communications and information handling, facing uncertainties, value formation, inquiry, and decision-making. Merryfield and White (1993) believe that teachers can organize and structure issues-centered global education on political, cultural/social, development, economic and environmental issues.

In summary, pedagogy for global education is the practice of teaching and learning global knowledge and content in ways that support human rights, diversity, social justice, world peace, and world citizenship. The use of appropriate instructional strategies for teaching of global knowledge and content is critical to helping students develop deeper understanding of what is going on around the world. When social studies teachers use appropriate framework and strategies in the classroom to teach current and controversial issues, they offer students the opportunity to develop critical and reflective thinking skills. Students experience, explore, analyze and participate in local and global projects. Many individuals have developed models that have helped many teachers teach from a global perspective.

Global educators have developed models that focus on providing a conceptual structure for teaching from a global perspective. All the models are interrelated and interdisciplinary. However, these models are concerned with and designed for 
kindergarten through twelfth grade (Alger \& Harf, 1986; C. Anderson, 1994; L. Anderson, 1990; Becker, 1979; Case, 1993; Kniep, 1986; Merryfield, 1997; Tye \& Tye,1992). Hanvey (1976) has developed a model that is more generic and easily adaptable to different settings including the collegiate level.

Conceptual Framework for the Study

This study is guided by the Hanvey Global Education Conceptual Framework.

The framework provides an appropriate college level structure for teaching from a global perspective. I also chose the Hanvey model because while making the transitions between the first dimension (perspective consciousness) to the fifth dimension (awareness of human choices), students develop a comprehensive view of self and others. In the process, they come to examine themselves and their role in the world. They come to respect others and their culture. I believe the stages or dimensions in the Hanvey model are closely linked to content, themes, values, and student skill development.

1. The five Hanvey (1976) global education conceptual dimensions are:

2. Perspective consciousness. This dimension addresses the recognition that one's own view of the world is not shared universally, that it is often shaped unconsciously, and that others have a view of the world profoundly different from one's own.

3. State-of-the-planet awareness. This dimension requires knowledge of prevailing world conditions and developments; and emerging trends such as population growth, migration, economic conditions, resources, and health.

4. Cross-cultural awareness. This dimension focuses on advancing understanding of the diversity of ideas and practices to be found in human society, and the mutual 
appreciation and understanding among cultures at the individual and societal levels.

5. Knowledge of global dynamics. This dimension describes the world as an interrelated systems characterized by interconnectedness and lack of predictability.

6. Awareness of human choices. This dimension requires an understanding of the problems of choice that confront individuals and nations.

Hanvey provides the vision and the universal values that can be taught and defended. Furthermore, Hanvey's model provides the essence of how differences and similarities in people and in cultures in the world can be taught and shared.

In one example of research conducted on the Hanvey model, Kirkwood (1995) provides examples of how the five Hanvey (1976) conceptual themes may be implemented across the disciplines. In her 1995 Miami-Dade County based study, she observed that teachers:

1. Teachers encouraged students to compare and contrast such things as the roles of family members, treatment of the elderly, child rearing, eating habits, and courtship patterns across cultures. In examining social customs and values in different parts of the world, students gained insights into various perspectives and began to see that others do not necessarily share their worldviews.

2. Teachers taught students to examine current events, to use maps to locate places in the world where the events occurred, and to link the currency of the events to historical patterns and themes. Most importantly, students were taught to speculate about the consequences of global events such as World Wars I and II, 
and whether these events would reoccur. In speculating about the effect of war, they come up with solutions.

3. Teachers encouraged students to engage in cross-cultural simulations. They invited guest speakers and developed pen-pal programs around the world.

4. Teachers taught students to understand the systemic and interdependent nature of events and issues. Students were taught to look for unintended consequences in their actions and behavior and to develop an understanding of how comparable cultural, ecological, economic, political, and technological systems work. Furthermore, she observed that global teachers emphasized the notion "Think globally and act locally" in classroom activities such as adopting a nursing home in other countries; conducting an anti-litter, aluminum can, or paper-drive campaign; having a sister school in a Third World country; studying the plight of immigrant groups in the community; examining the various aspects of local problems such as homelessness and poverty; and developing student projects towards the elimination of these problems on the local level.

Summary

This chapter presented a review of selected literature on global education and global pedagogy relevant to the purpose of the study. The subsections included brief discussions on globalization, constructivism, global education and pedagogy for teaching global education. The Hanvey Global Education Conceptual Framework was also presented. It is the conceptual model of this study. 


\section{CHAPTER III}

\section{METHODS}

This chapter describes the methods used in this study. A mixed methods design was chosen to provide a more integrated approach to identifying the global knowledge and global mindedness teachers have and the instructional strategies they use in teaching global perspectives. This approach allowed the researcher to use multiple data sources, data collection techniques, and methods of data analysis (Tashakkori \& Teddlie, 2003).

Two survey instruments, the Global Awareness Survey and the Global Mindedness Scale were chosen for this study because they have been previously found to be useful by global education researchers in Miami-Dade County and elsewhere. In addition to this quantitative element to this study, qualitative data was also gathered and analyzed from observations, interviews, field notes, and document analysis (Berg, 2001).

The problem that was investigated in this study lends itself to a mixed ANOVA design. A repeated-measures design was used because results from the global knowledge and global mindedness scales could be converted to numerical data. Therefore individuals were matched on two variables so that individuals within a set are similar on the matching variables. The number of individuals within a set is equal to the number of levels of a factor. The individuals within a set were then observed under the various levels of each factor. Morgan and Griego (1998) observed that a mixed model involves both between subjects/groups and within subjects analyses. They argue that in a mixed ANOVA design, the researcher can also investigate between factors as well as the effect of individual factors on one or more dependent variables. In this study, after the scores 
were transformed, the researcher compared the standard scores with the means of raw scores for the three groups on global knowledge and global mindedness.

The methods selected are appropriate considering the nature of the study and the research questions. One of the advantages of mixed methods is that a problem can be examined or investigated using both qualitative and quantitative data and interpretations. Tashakkori and Teddlie (2003) have argued that this approach results in stronger research because it rejects the either-or limitations of the exclusively quantitative or qualitative approaches. In this study, this research design was chosen because in addition to (quantitatively) knowing what global knowledge the secondary teachers had, the researcher wanted to find out how global knowledge was (qualitatively) being applied in the classroom. Specifically, how a teacher begins his or her instruction, leads a class discussion, uses concepts or themes, uses a conceptual framework, and a variety of instructional strategies in teaching from a global perspective (Borich, 2003). Educational researcher Berg (2001) has written that by combining several lines of sight, researchers obtain a better, more substantive picture of reality, a richer, more complete array of symbols and theoretical concepts, and a means of verifying many of these elements. In this study, qualitative data was collected from secondary teachers in order to obtain a deeper and substantive understanding of the reality of social studies curriculum and instruction in those classrooms. Specifically the qualitative research project focused on clarifying how these teachers dealt with the following concepts: human interconnectedness, interdependence of systems, multiple perspectives, world citizenship, and world peace. 


\section{Research Questions}

The first three of five research questions compare levels of knowledge and global mindedness among the three groups of teachers. The first research question addressed in this study asks if there is a significant difference among teachers trained in Globally Oriented Social Studies Education (GOSSE) programs, those trained in non-Globally Oriented Social Studies education (non-GOSSE) and Teachers Who Teach Other Subjects (TWTOS) in their global knowledge and global mindedness. The second asks if there a significant difference between teachers in the GOSSE group and the nonGOSSE/TWTOS group in their global knowledge and global mindedness. The third asks if there a significant difference between teachers in GOSSE/non-GOSSE and TWTOS groups in their global knowledge and global mindedness.

The fourth question asks about possible relationships between age, gender, and years of teaching experience and teachers' global knowledge and global mindedness. The rationale for asking about the teachers' ages and length of time they have been teaching is that the researcher assumed that the older teachers get and the longer they teach the more global knowledge and global mindedness they seem to attain. The final research question asks if teachers from the GOSSE group teach from a global perspective and infuse global perspectives into the curriculum differently than teachers from the nonGOSSE groups

Hypotheses

The null hypotheses for this study are:

1. There is no significant difference among teachers in the GOSSE, non-GOSSE and TWTOS groups in their global knowledge and global mindedness. 
2. There is no significant difference between teachers in the GOSSE and nonGOSSE/TWTOS groups in their global knowledge and global mindedness.

3. There is no significant difference between teachers in the TWTOS and nonGOSSE/GOSSE groups in their global knowledge and global mindedness.

4. There is no relationship between age, gender, and years of teaching experience in teachers' global knowledge and global mindedness.

\section{Setting}

This study was conducted in 34 senior high schools in Miami-Dade County Public Schools (M-DCPS). M-DCPS is the fourth largest school system in the United States. At the time of the study it had 315 schools. Also at the time of the study, within these schools were more than 385,000 students, $87 \%$ of whom were Hispanic or African American, and 32,000 teachers. Many (approximately 74\%) of the secondary school teachers in the study were educated at Florida International University's (FIU) College of Education. This is not surprising because over $50 \%$ of the graduates of this public university are currently teaching in South Florida (FIU, College of Education, 2003). Through FIU's Department of Curriculum and Instruction's social studies/global education program, $63 \%$ of the social studies participants were trained in developing and infusing global education into their curriculum. Thirty seven percent of the social studies participants had their education and training in other programs or at other institutions.

The social studies/global education program at FIU has been recognized as a globally oriented program, and a model for all the teacher-training programs of global education in the nation (Merryfield, 1992). The program is designed to provide pre- and in-service elementary, middle, and high school social studies teachers with the 
knowledge, skills, and disposition they will need to meet the challenges of teaching in a culturally diverse and globalized world. The program is guided by the four COE core concepts: (a) interculturalism, (b) interdependence, (c) inquiry and (d) instructional leadership. Connected to these college-wide concepts, the goal of the program is to prepare pre- and in-service teachers to be educators who will be able to provide their students with the knowledge, skills, and disposition necessary to meet the demands of, and to function productively in, an increasingly interconnected and interdependent world. One of the characteristics of the program is in the training of the pre-and inservice social studies teachers in developing and infusing global education in the classroom. Other characteristics include: (a) being an in-depth program of study (b) having a summer institute, (c) offering study tours and (d) having extended inservice workshops.

A key component of the social studies education program of study is the SSE 4380/SSE 5381 course designed to expose students to the theory, content, and practice of global education. It is a required course for all pre-service social studies teachers who are enrolled in the secondary social studies education program at FIU, including students who have finished 60 lower division credits and those with a bachelor's degree in an area other than education, but seeking a master's degree in secondary social studies education. Learning strategies and materials are used to demonstrate why a global perspective is an important element of social studies education, and how a global perspective can be infused into social studies curriculum and instruction.

The main objectives of the course are to prepare a social studies teacher who will: (a) understand the theories, purpose, rationale, and content of global education; (b) be able to identify the instructional relationships between global education and individual 
subject areas and grade levels; (c) be able to select, design, and implement content, learning materials and instructional strategies which infuse a global perspective into subject areas and grade levels, and provide learning experiences that move the learner toward acquiring a global perspective; (d) be able to master global-related, computerbased technology for classroom use; and (e) be disposed toward infusing a global and multicultural perspective into the school curriculum (Tucker, 1996).

\section{Participants}

For the purposes of administering the surveys, a total of 90 participants were randomly selected from the population of M-DCPS secondary teachers and assigned to three groups to determine whether levels of global knowledge and global mindedness differ among groups, and whether teachers' global knowledge and global mindedness are correlated with their age, gender, and years of teaching experience. Group 1 consisted of social studies teachers who were trained in FIU's globally oriented program (GOSSE). Group 2 consisted of social studies teachers who were trained in other social studies programs and/or in other institutions (non-GOSSE). Group 3 consisted of teachers who teach other subjects (TWTOS). Because teachers in Group 3 were exposed to the same students as social studies teachers, it was decided that they be included in the quantitative part of the study.

The data gathered came from teachers who were teaching in M-DCPS or working toward their masters or doctoral degrees in FIU's College of Education in Miami, Florida. Of the teachers who completed the surveys, several were chosen for observation. In the qualitative data collection phase of this study, seven social studies teachers, two of whom team-taught a class, drawn from GOSSE and non-GOSSE training 
programs were observed in order to compare the instructional strategies they used in teaching global perspectives. All teachers who were chosen had demonstrated high levels of global knowledge on the survey. These seven participants were purposefully selected to ensure that there was approximately equal representation between GOSSE and non-GOSSE teachers. Three female teachers and four male teachers were selected. Qualitative data were collected during 60 hours of classroom observation, completed within a period of 12 weeks (see Appendix G).

\section{Instrumentation}

The two survey instruments used to gather quantitative data for this study were carefully selected to ensure statistical and non-statistical accuracy. The Test of Global Knowledge and the Test of Global Mindedness scales were both adapted for this study. The Educational Testing Service (ETS, 1981) administers the Global Knowledge Scale. Jane Hett (1993) developed the Global Mindedness Scale.

\section{Global Knowledge Scale}

The Test of Global Knowledge is part of ETS's Global Awareness Survey Instrument ( Reprinted by permission of Educational Testing Service, 1981). This survey instrument was developed as a measure of college students' global understanding. It contains four main sections. One inquires about students' background information, a second about their foreign language proficiency, a third concerning their global knowledge, and a fourth about their global attitudes and perceptions. The survey consists of 91 multiple-choice knowledge questions divided into 13 topics: environment, food, health, energy, religious issues, arts and culture, distribution of natural characteristics, relations among nations, war and armaments, international monetary and trade 
arrangements, human rights, racial and ethnic issues, and population growth. The Test of Global Knowledge has Cronbach's alpha reliability coefficients of .84 for freshmen, .86 for seniors, and .87 for 2-year college students (Klein \& Ager, 1981).

In this study, the Test of Global Knowledge was modified and consisted of 50 multiple-choice knowledge questions divided into four themes: world history/conflicts, world geography/cultures, world economy/systems, and world politics. The assessment instrument was modified to be brief enough to encourage teachers to voluntarily complete it. The specific questions chosen were relevant to global education and M-DCPS social studies curricula. The content validity of this instrument was based on input from two social studies experts at FIU. It was assumed that the reliability of the instrument would be affected by the modification but that the effect was small because all of the questions relating to the four themes were included while the questions that were eliminated were questions regarding other social issues such as the arts, health and food.

The Global Awareness Survey Instrument and its modified versions have been used effectively by several researchers in studies measuring the global understanding of different groups of people (Cogan, 1988; Masolwa, 1995; Torney-Purta, 1985; Zong, 1999). Approximately 3,000 students, freshmen in 4-year institutions and students in 2 year colleges in the United States, who attend a total of 185 institutions, have taken adapted versions of the original instrument (Barrow 1981; Zong, 1999). Torney-Purta (1985) adapted the instrument and used it to measure the global knowledge of approximately 1,500 secondary school students in nine states in the United States. Masolwa (1995) also conducted a study using the instrument. He compared global attitudes of senior students enrolled in teacher education programs and senior students 
enrolled in corresponding majors outside the teacher education programs at the University of South Carolina. Global Mindedness Scale (GMS)

The Global Mindedness Scale consists of 30 items (Reprinted by permission of Jane Hett, University of San Diego, 1993). Hett (1993) has indicated that the creation of the instrument was guided by research, which focused on world-mindedness, international understanding, feminist theory, and education. Moreover, she has indicated that inductive data triangulation, content validity determination, and a pilot study were also used to help finalize the construction of the instrument. In this study, the Global Mindedness Scale provides an appropriate measure for testing social studies teachers' attitudes. The scale measures global mindedness along five theoretical dimensions: responsibility, cultural pluralism, efficacy, global centrism, and interconnectedness. The response to questions contained in the five sub-scales provided data for arriving at the global-mindedness score.

Hett (1993) correlated the Global-Mindedness Scale's (GMS) concurrent and construct validity with other instruments and found a negative correlation of -.65 , at the .001 level of significance. A significant correlation was established between the GMS and Barrows's Chauvinism Scale (1981). Hett (1993) selected Yachimowicz's International Scale (ICS, 1988) and found a correlation of .32 between GMS and ICS. Construct validity was further established through factor analysis and analysis of variance that were conducted to analyze for significant differences on criteria established by the literature and through qualitative research (Zong, 1999). Furthermore, Hett (1993) tested the Global-Mindedness Scale with undergraduate students at the University of California, 
San Diego and found that GMS scores differed significantly by gender, academic experience, political views, participation in internationally oriented activities, and international experience.

Gillan (1995) used the GMS to measure the global-mindedness of 878 students along with selected faculty members and administrators at the University of Northern Colorado. Significant differences in global-mindedness were found on the GMS composite between study abroad students and non-study abroad students. The sub-scores of the study abroad students exhibited a greater global-mindedness. Female students, on the average ( $n=114)$ were more global-minded than males $(n=108)$. Gillan's study confirmed that the Global-Mindedness Scale was a reliable instrument in assessing the global-mindedness of a variety of populations. Permission to use the Global Mindedness Scale was sought and granted for this study.

Procedure of Survey Administration

Approval to administer the study was given by M-DCPS Office of Evaluation and Research. A letter was sent to all the principals explaining the significance of the study and asking them to assist in encouraging full participation. A follow up letter and email was sent to remind the principals of the study. Some principals decided not to have their teachers participate in the study. Others met with the chairs to inform them that the researcher would be coming to the school. Surveys and consent forms were then brought to each of the public high schools in the county by the researcher. The researcher met with each school's social studies department chair. The chair was given an overview of the study and enough surveys and consent forms for the social studies teachers in that school. Chairs then were asked to distribute and collect the materials. The chairs 
contacted the researcher when it was time to pick up the completed surveys and consent forms.

\section{Observation Guide}

An observation guide was developed based on the five dimensions of the Hanvey Model (1976). Teachers were observed to determine whether these dimensions were applied and integrated into their lessons:

1. Perspective Consciousness. The researcher observed to see if teachers were facilitating perspective consciousness by providing opportunities for students to examine the multiple perspectives held by different people on historical and contemporary events and issues.

2. State-of-the Planet Awareness. The researcher observed to see if teachers were integrating state of the planet awareness by helping students to analyze the causes, consequences, and possible solutions to both emerging and persistent global issues. Issues may include national security, resource allocation, economic development, environmental quality and international current events.

3. Cross-Cultural Awareness. The researcher observed to see if teachers were infusing cross-cultural awareness by helping students understand the diversity of ideas and practices to be found in human societies and to develop respect and empathy for others who are different.

4. Awareness of Global Dynamics. The researcher observed to see if teachers were incorporating the knowledge of global dynamics by assisting students in understanding the interconnectedness of the world as a system, and the 
linkage between South Florida and the world. Guiding students' analysis of relationships and tensions between national sovereignty and global interests in such matters as territorial disputes, economic development, nuclear and other weapons deployment, use of natural resources, human rights concerns and helping students to describe and evaluate the role of transnational organizations in the global arena.

5. Awareness of Human Choices. The researcher observed to see if teachers were including an awareness of human choices by having students understand how individual behaviors and decisions connect with global systems, and how they can assume a responsibility in contributing toward a better world (Hanvey, 1976).

\section{Qualitative Component}

For the qualitative data segment of this study, field notes, interviews, observational notes, and lesson plans were used. Lessons observed were based on a Competency-Based Curriculum ( $\mathrm{CBC}$ ). The $\mathrm{CBC}$ was the mandated curriculum in the schools where data were gathered. The challenge for the researcher in this project was to make sense of the massive amount of data, to reduce the volume of information, identify teachers' global thinking and the appropriate instructional strategies they used, and to link the latter to the Hanvey conceptual themes.

Non-participant Classroom Observation

Non-participant observation offered the investigator the opportunity to observe the teachers in their natural setting (Bogdan \& Biklen, 1992). The purpose of the nonparticipant classroom observation was to see and experience firsthand how the selected 
social studies teachers infused global theory and how they used both the CompetencyBased Curriculum standards and a global perspective in the classrooms.

The classroom observations were conducted during the months of February, March, and April 2003. Initially, the researcher met with each teacher for 15 minutes each to discuss the purpose of the study. During the initial meeting, the researcher introduced himself and reviewed the content in the consent form with each teacher. The follow-up visits lasted the entire class period, which was about 2 hours. In total, over 60 hours of classroom observation data were collected. The researcher observed, took notes, and cross-referenced notes to determine whether issues-centered strategies and global content were evident, and whether the five global dimensions were infused in the teaching. The teachers were informed and arrangements were made to visit each classroom at the teacher's discretion and convenience. Since assurance of confidentiality and anonymity has been granted to all participants, pseudonyms are used in this report for teachers participating in the study.

In some ways the researcher was an educational connoisseur in this study. According to Eisner (1991) an educational connoisseur is someone who talks to people and listens to what they have to say. Shortly after each classroom observation, I had a discussion with the teacher who had been observed in order to determine the teacher's perception of the lesson. Eisner has written that interviewing and discussion are powerful resources for learning about how people perceive situations, in this case - their teaching in a secondary classroom. It is in this framework that the concept of connoisseurship was applied to this study. Validity in connoisseurship is determined through structural corroboration and referential adequacy. The former refers to how the puzzle fits together 
credibly and recognizably. Referential adequacy refers to comparing the descriptions and observations of the problem or phenomenon to what is actually being observed. It was assumed that classroom instruction would reflect teachers' global knowledge and attitude about teaching global education.

Each of the selected seven social studies teachers was observed four times for 2 hours each time between February and April 2003 to determine whether instructional strategies differed among the seven teachers. Teachers trained in the GOSSE program had gone through a globally oriented social studies and global education program at Florida International University, where they took a course in Developing a Global Perspective, and attended workshops and seminars in global education. Thus, for this study, they were assumed to be familiar with the Hanvey model.

Each observation lasted an entire class period; most lasted two hours (block scheduling). The classroom observations did not address classroom management techniques or other issues in the classroom. To increase credibility, whenever possible the researcher read copies of lesson plans and handouts used during the class. Field notes were taken that described what was going on in the classroom. Immediately after each observation, the researcher held a discussion of approximately 20 minutes with the teacher (Bogdan \& Biklen, 1992). Notes pertaining to these discussions and the field notes were later expanded and organized into a manageable series of electronic files. In order to further enhance accuracy in the analysis of data, after each observation the researcher also wrote his reflections on the themes, the model, and what he had observed in the classroom. 
Analyzing qualitative data is a process that brings order to the data by organizing content into patterns, categories, and descriptive units (Patton, 1988). Data from classroom observations and from discussions after the lessons were compared and aligned with the Hanvey conceptual themes.

The five Hanvey dimensions provide the organizing framework for analyzing and synthesizing the observational data. According to Fraenkel and Wallen (1993) data analysis involves synthesizing the information the researcher obtains from various sources into a coherent description of what he or she has observed or otherwise discovered.

Classroom observation data from the field notes were coded according to a series of guided questions that had been organized into the following Hanvey model categories: teaching global concepts, facilitating perspective consciousness, integrating the state-ofthe-planet awareness, infusing cross-cultural awareness, incorporating the knowledge of global dynamics, and including the awareness of human choices (Hanvey, 1976). Researchers suggest that gathering qualitative data should begin very early and continue throughout the study (Maxwell, 1988). Toward this goal, in this study the researcher observed over a three-month period. During the process of classroom observation, the researcher was careful in looking for whether the goal of global education - the interconnectedness of major global themes and concepts, was evident during instruction.

According to Maxwell (1998), careful observation of themes and concepts during observation helps to validate the emerging conclusions. At the completion of observations, all items on the observation guide, all the coded fieldnotes, and the written reflections were studied and analyzed in their entirety. Finally, interpretations of and 
conclusions about the data were compared with what had been found in past studies to support the analyses and interpretations of data (i.e., Benitez, 2001; Cruz, 1990;

Kirkwood, 1995; Tucker, 1983; Zong, 1999). Bogdan and Biklen (1992) maintain that a researcher could use any one or a combination of settings and context codes, process codes, activities codes, strategy codes, relationship and social structure codes, and pre assigned coding schemes to sort out qualitative data. The pre-assigned coding used in this study was based on the Hanvey Global Education model.

Criteria for Evaluation of Teachers' Global Knowledge, Global Awareness, and Instructional Practices

For this study, the following criteria were used for analyzing teachers' instructional practices in the classroom:

Teacher's global knowledge. Does the teacher demonstrate knowledge of global events and issues in the classroom? Does the teacher allow for the exploration of controversial issues? The indicator was an ability to apply his or her global knowledge during all teaching and learning activities.

Teacher's pedagogical knowledge and skills. Does the teacher demonstrate appropriate pedagogical knowledge? This is the ability to use appropriate, meaningful, and relevant strategies in the classroom. The indicators were: The strategies observed and described in the questionnaire (see Appendix G). Specifically, the use of hands-on learning activities and materials including, role-playing, simulations, discussions, lesson plans (thoughtfulness, planned instruction, reflection).

Teaching style and resources. Does the teacher encourage students to compare and contrast information, examine current events, and use various resources? Do 
students have access to a variety of resources (i.e., Internet access, media center, library facilities, resources in the community, newspapers, magazines, VCR)? The indicators were: The ability to teach concepts and theories that explain how the world systems of interconnectedness and interdependence work.

Multiple perspectives. Does the teacher present multiple, diverse, and competing perspectives? Does the teacher engage students in cross-cultural dialogue? The indicators were: The ability to use diversity within the classroom to explain how the world is different, and the ability to use perspective consciousness, a consciousness that gives students a sense that they are members of a global community (Hanvey, 1976).

Philosophy of teaching. Does the teaching demonstrate a philosophy of education that aligns well with global pedagogy? Does the teaching appear to be based on a conceptual framework or model that aligns well with global education? The indicator was: The ability to use an appropriate conceptual framework or a model to guide the planning and writing of a lesson plan. For example, if the teacher is guided by a humanistic philosophy, their approach will support child-centered instruction and a constructivist pedagogy. In this approach, the teacher guides students as they construct and reconstruct knowledge through projects and activities.

\section{Summary}

The purpose of this chapter was to present the methods and procedures used for this study. A mixed method was chosen to provide a more integrated approach in answering the research questions. The research design, participants, instrumentation and setting of the study were described. Additionally, pertinent data collection and analysis procedures were outlined. 


\section{CHAPTER IV}

\section{RESULTS}

This chapter presents the results of the study in two parts, quantitative and qualitative. In doing so, a brief description of the sample is given, followed by analyses of the data collected. Findings on the relationship between teachers' global knowledge, global mindedness, and instructional strategies are also presented. Because this study was intended to examine factors that contributed to teachers' global knowledge, global mindedness, and the instructional strategies used as well as the potential influences of degree, age, gender and years of teaching experience, the level of confidence was set at $\alpha=.10$. However, for the post-hoc comparisons $\alpha=.05$ was used to control family-wise Type 1 error. To permit comparison and analyses of Global Knowledge and Global Mindedness (Global Thinking) scores in a mixed ANOVA, the two sets of raw scores were standardized (Gall, Gall, \& Borg, 1996).

\section{Demographic Data}

Ninety high school teachers in selected Miami-Dade County Public Schools responded to the Global Knowledge and the Global Mindedness surveys. They were divided into three groups. Group 1 consisted of teachers who had attended a globally oriented social studies education program (GOSSE). Teachers in this group have taken a preparatory course on how to teach from a global perspective at FIU in the College of Education. Group 2 consisted of teachers from other programs or other institutions' social studies education programs (non-GOSSE). Group 3 consisted of teachers who teach other subjects such as language arts, science, math, and ESOL (TWTOS). The researcher believes that teachers in Group 3 can contribute to students' global knowledge 
and global understanding, because adding a global dimension or teaching from a global perspective is not limited only to social studies teachers. The demographic data for Age, Gender, Ethnicity, and Years of Teaching Experience are presented in Table 1.

Table 1

Participant Demographic Data $(n=90)$

\begin{tabular}{|c|c|c|c|c|c|c|}
\hline \multirow[b]{2}{*}{ Variable } & \multicolumn{2}{|c|}{ GOSSE } & \multicolumn{2}{|c|}{ Non-GOSSE } & \multicolumn{2}{|c|}{ TWTOS } \\
\hline & $n$ & $\%$ & $n$ & $\%$ & $n$ & $\%$ \\
\hline \multicolumn{7}{|l|}{ Age } \\
\hline $20-30$ & 8 & 27 & 12 & 40 & 7 & 23 \\
\hline $31-40$ & 5 & 17 & 5 & 17 & 11 & 37 \\
\hline $41-50$ & 8 & 27 & 11 & 37 & 9 & 30 \\
\hline $50+$ & 9 & 30 & 2 & 7 & 3 & I0 \\
\hline \multicolumn{7}{|l|}{ Gender } \\
\hline Female & 12 & 40 & 18 & 60 & 18 & 60 \\
\hline Male & 18 & 60 & 12 & 40 & 12 & 40 \\
\hline \multicolumn{7}{|l|}{ Ethnicity } \\
\hline White & 8 & 27 & 2 & 7 & 4 & 13 \\
\hline Black & 2 & 7 & 1 & 3 & 3 & 10 \\
\hline Hispanic & 12 & 40 & 8 & 27 & 4 & 13 \\
\hline Other & 8 & 27 & 19 & 63 & 19 & 63 \\
\hline \multicolumn{7}{|l|}{$\begin{array}{l}\text { Years of } \\
\text { Teaching } \\
\text { Experience }\end{array}$} \\
\hline $0-10$ & 14 & 47 & 21 & 21 & 19 & 63 \\
\hline $11-20$ & 16 & 53 & 9 & 30 & 11 & 37 \\
\hline \multicolumn{7}{|l|}{ Degree } \\
\hline Bachelors & 10 & 33 & 11 & 37 & 12 & 12 \\
\hline Masters & 10 & 33 & 10 & 33 & 10 & 33 \\
\hline Specialist & 6 & 20 & 9 & 30 & 6 & 20 \\
\hline Doctoral & 4 & 13 & 1 & 3 & 2 & 6 \\
\hline
\end{tabular}


In the Miami-Dade County School district, ali elementary and secondary school teachers are required to add multicultural and global dimensions in their classroom instruction. Teachers, who participated in this study represented the diverse multicultural backgrounds found in Miami-Dade County School district. Ninety percent of the participants were between 20 and 30 years of age. Ninety four percent are between 41 and 50 years of age. Female teachers represented $53 \%$ of the sample, while $47 \%$ were male. Twenty seven percent of the participants were Hispanic. Fifteen percent were White, and seven percent were Black. Sixty percent of the participants had less than 10 years of teaching experience. Forty percent had more than 10 years of teaching experience. Thirty seven percent of the participants had a bachelor's degree. Thirty three percent of the participants had a master's degree. Twenty three percent had a specialist degree. Seven percent had a doctoral degree. The Chi-square test shows that there is no significant difference between the age, gender, and ethnicity of the participants and the participants' global knowledge and global mindedness. The analysis of the quantitative data is presented in the next section.

\section{Analysis of Quantitative Data}

This part of the study was designed to answer four quantitative research questions: Is there a difference among teachers in GOSSE, non-GOSSE, and TWTOS programs in their global thinking (i.e. global knowledge and global mindedness)? Is there a difference between teachers in GOSSE and in both non-GOSSE and TWTOS programs in their global thinking? Is there a difference between teachers in both GOSSE and non-GOSSE and TWTOS programs in their global thinking? Is there a relationship between degree, age, gender, and years of teaching experience in teachers' global 
thinking? The summary of means and standard deviations of global thinking by groups is presented in Table 2 .

Table 2

Summary Table of Means and Standard Deviation of Global Thinking by Group Membership

\begin{tabular}{|c|c|c|c|c|}
\hline \multirow[b]{2}{*}{ Group } & \multicolumn{2}{|c|}{ Global Mindedness } & \multicolumn{2}{|c|}{ Global Knowledge } \\
\hline & $M$ & $S D$ & $M$ & $S D$ \\
\hline GOSSE & 48.86 & 10.51 & 54.66 & 10.66 \\
\hline $\begin{array}{l}\text { Non- } \\
\text { GOSSE }\end{array}$ & 51.65 & 10.02 & 45.51 & 9.64 \\
\hline TWTOS & 49.48 & 9.56 & 49.82 & 7.84 \\
\hline
\end{tabular}

Because the instrument was modified, the norms set for the unmodified instrument would not be appropriate. Therefore, the overall average of raw scores for the group $(M=26.72, S D=6.89)$ was used as the reference to determine the average. The standardization of the data results in this average translating to a score of 50 with a standard deviation of 10 .

As shown in Table 2, the standardized means and standard deviations for global mindedness and global knowledge revealed that the means for global mindedness range from 48.86 to 51.65 and the standard deviations range from 9.56 to 10.51 , indicating that the variances are not significantly different from each other. The means for global knowledge range from 45.51 to 54.66 and the standard deviations range from 7.84 to 10.18 , indicating that the variances are slightly different from each other. The summary 
of the raw and transformed means and standard deviations of global knowledge by groups is presented in Table 3.

Table 3

Summary of Means of Raw Scores for Three Groups on Global Knowledge

\begin{tabular}{lccccc}
\hline & \multicolumn{2}{c}{ Raw Score } & & \multicolumn{2}{c}{ Standardized Score } \\
\cline { 2 - 3 } \cline { 5 - 6 } Group & $M$ & $S D$ & & $M$ & $S D$ \\
\hline GOSSE & 29.93 & 7.02 & & 54.66 & 10.66 \\
$\begin{array}{l}\text { Non- } \\
\text { GOSSE }\end{array}$ & 23.63 & 6.86 & & 45.51 & 9.64 \\
TWTOS & 26.60 & 5.37 & & 49.82 & 7.84 \\
\hline
\end{tabular}

The mean for Group1 $(M=29.93)$ was above the average raw score. The mean for Group $2(M=23.63)$ was below the raw average score. The mean for Group $3(M=$ 26.60) was average. However, as seen in Table 4 the scores for Global Mindedness reflect a different trend. Table 4 presents the summary of the raw and transformed means and standard deviations of global mindedness by groups. The overall average raw score for Global Mindedness is 105.42. The mean for Group1 $(M=103.97)$ was below the average raw score. The mean for Group $2(M=107.53)$ was above the raw average score. The mean for Group $3(M=104.77)$ was average. An ANOVA test on the standardized data determined whether the differences are significant. The GOSSE group appears to have greater global knowledge than average but they are less globally minded. 
Table 4

Summary of Means of Raw Scores for Three Groups on Global Mindedness

\begin{tabular}{|c|c|c|c|c|}
\hline \multirow[b]{2}{*}{ Group } & \multicolumn{2}{|c|}{ Raw Score } & \multicolumn{2}{|c|}{ Standardized Score } \\
\hline & $M$ & $S D$ & $M$ & $S D$ \\
\hline GOSSE & 103.97 & 13.43 & 48.86 & 10.51 \\
\hline $\begin{array}{l}\text { Non- } \\
\text { GOSSE }\end{array}$ & 107.53 & 12.82 & 51.65 & 10.02 \\
\hline TWTOS & 104.77 & 12.22 & 49.48 & 9.56 \\
\hline
\end{tabular}

Global Knowledge

As shown in Table 5, there is a significant difference between groups: $F(2,87)=$ $7.15, p<.05$ on global knowledge. The null hypothesis is, therefore, rejected. It is concluded that at least one group is different in their global knowledge. A Tukey posthoc test was conducted to determine the loci of the difference and control for Type 1 error across the multiple pairwise comparisons. The post-hoc revealed that GOSSE ( $M=$ 54.66), differs from non-GOSSE $(M=45.51)$ and TWTOS $(M=49.82)$ in the level of global knowledge. It is concluded that the mean scores for global knowledge for GOSSE was significantly higher on global knowledge than that of non-GOSSE and TWTOS groups. Table 5 presents a summary of the ANOVA of the interaction of Global Knowledge and Global Mindedness standardized scores. 
Table 5

Summary of ANOVA Showing the Interaction of Global Thinking and Group Membership

\begin{tabular}{lrrrrr}
\hline Source & $d f$ & \multicolumn{1}{c}{$S S$} & $M S$ & $F$ & $p$ \\
\hline & \multicolumn{5}{c}{ Global Knowledge } \\
Groups & 2 & 596.02 & 298.01 & 7.15 & $<.05$ \\
MSEb & 87 & 3628.03 & & \\
\hline & & Global Mindedness & \\
Groups & 2 & 210.15 & 105.07 & .64 & \\
MSEb & 87 & 14337.87 & & \\
Total & 89 & 4547.95 & & \\
\hline
\end{tabular}

Global Mindedness

As shown in Table 3, there is no significant difference between groups: $F(2,87)$

$=0.64, p<.10$ on global mindedness. The null hypothesis is not rejected. $1 \mathrm{t}$ is concluded that the mean scores for global mindedness of GOSSE $(M=48.86)$, although lower than non-GOSSE $(M=51.65)$, and TWTOS $(M=49.48)$ were not statistically different from each other.

Main Effects

An overall $3 \times 2 \times 2 \times(2)$ mixed analysis of variance (ANOVA) was conducted to determine the relationship between group membership, gender and years of teaching experience and Global Thinking. The between-subjects variables were: Group Membership (GOSSE, non-GOSSE, and TWTOS), Gender (female and male), and Years 
of Teaching Experience $(0-10$ and $11-20)$. The within-subjects variable was the Global Thinking score (global knowledge and global mindedness). As shown in Table 4, the between subjects main effect of Group Membership (GM) was significant, $F(2,78)$ $=2.43, p=0.09$, as was the interaction of GM and GT, $F(2,78)=5.59, p=0.05$. A Bonferroni post hoc comparison of the three means of main effect of Group Membership and the interaction of $\mathrm{GM} \times \mathrm{GT}, F(1,78)=2.69, p=0.10$ showed that the mean for GOSSE $(M=54.66)$, was significantly higher than that for non-GOSSE $(M=45.51)$ and TWTOS $(M=49.82)$. None of the other main effects or interactions was significant.

The difference between non-GOSSE and TWTOS was not significant at $p<0.05$. Overall, this shows that teachers in the globally oriented program (GOSSE) had a higher level of mastery of global knowledge than teachers in the non-GOSSE and TWTOS program groups.

Interaction of Groups and Global Thinking

The main effect of Group Membership is qualified since the interaction of Group Membership and Global Thinking was significant, $F(2,78)=5.59, p<0.05$. To examine the loci of the interaction, the two components of Global Thinking (i.e., Global Knowledge and Global Mindedness) were analyzed, separately. In Table 6, the Summary of a mixed ANOVA of Global Thinking Scores is presented. In Table 7, the interaction of Global Thinking by Groups is also presented.

A two-way ANOVA of GOSSE and non-GOSSE programs and TWTOS are presented. There is a significant difference between GOSSE and non-GOSSE/TWTOS, $F(1,88)=10.86$ on Global Thinking. The null hypothesis is, therefore, rejected. 
Table 6

Summary Table of a Mixed ANOVA of Global Thinking Scores

\begin{tabular}{lcccc}
\hline Source & $d f$ & $M S$ & $F$ & $p$ \\
\hline & & \multicolumn{3}{c}{ Between Subjects } \\
Group Membership (GM) & 2 & 2.17 & 2.43 & .09 \\
Gender (GE) & 1 & .04 & .04 & .95 \\
Years of Teaching & 1 & .98 & 1.10 & .30 \\
Experience (E) & 2 & .68 & .76 & .47 \\
GM $\times$ GE & 2 & .09 & .11 & .90 \\
GM $\times$ E & 1 & .53 & .59 & .45 \\
GE $\times$ E & 2 & .46 & .52 & .60 \\
GM $\times$ GE $\times$ E & 78 & .89 & & \\
MSE & & & & \\
\hline
\end{tabular}

Within Subjects

\begin{tabular}{lcccc} 
Global Thinking $(\mathrm{GT})$ & 1 & .10 & .10 & .78 \\
$\mathrm{GM} \times \mathrm{GT}$ & 2 & 5.65 & 5.59 & .05 \\
$\mathrm{GE} \times \mathrm{GT}$ & 1 & 2.72 & 2.69 & .10 \\
$\mathrm{E} \times \mathrm{GT}$ & 1 & 1.95 & 1.93 & .17 \\
$\mathrm{GM} \times \mathrm{GE} \times \mathrm{GT}$ & 2 & 1.17 & 1.15 & .32 \\
$\mathrm{GM} \times \mathrm{E} \times \mathrm{GT}$ & 2 & .13 & .13 & .27 \\
$\mathrm{GE} \times \mathrm{GE} \times \mathrm{GT}$ & 1 & .13 & .14 & .71 \\
$\mathrm{GM} \times \mathrm{GE} \times \mathrm{E} \times \mathrm{GT}$ & 2 & .89 & .88 & .42 \\
MSEw & 78 & 1.01 & & \\
\hline Note $:$ Global Thinking is a combined score of global knowledge and global mindedness tests.
\end{tabular}


Table 7

Summary of ANOVA Showing the Interaction of Global Thinking and GOSSE and NonGOSSE and TWTOS

\begin{tabular}{lccccc}
\hline Source & $d f$ & $S S$ & $M S$ & $F$ & $p$ \\
\hline & \multicolumn{5}{c}{ Global Knowledge } \\
Groups & 1 & 997.65 & 977.65 & 10.86 & $<.01$ \\
MSEь & 88 & 7922.35 & 90.03 & \\
\hline & & Global Mindedness & \\
Groups & 1 & 58.33 & 58.33 & .58 & $>.45$ \\
MSEь & 88 & 8841.67 & 100.47 & \\
Total & 90 & 2333900.00 & & \\
\hline
\end{tabular}

It is concluded that mean Global Thinking scores for the GOSSE program were significantly higher in their Global Thinking than that in non-GOSSE and TWTOS program means. The interaction between GOSSE and non-GOSSE/TWTOS was not significant, $F(1,88)=.58, p=0.45$ on global mindedness. It is concluded that teachers in GOSSE program were not different on their global mindedness than teachers in nonGOSSE/TWTOS.

Survey Analysis Summary

The analysis of the survey data indicates that teachers from the GOSSE program are significantly different in their level of global knowledge than those from non-GOSSE and in TWTOS programs. Therefore, Hypothesis 1 that stated that there is no significant difference among teachers in GOSSE, non-GOSSE, and TWTOS programs in their 
global knowledge is rejected. The hypothesis for global mindedness is not rejected. Hypothesis 2 that stated that there is no significant difference between teachers in GOSSE and non-GOSSE/TWTOS programs in their global knowledge and global mindedness is not rejected. Hypothesis 3 that stated that there is no significant difference between teachers in GOSSE and non-GOSSE/TWTOS in their global knowledge and global mindedness is not rejected. Hypothesis 4 regarding the relationship between degree, age, gender, and years of teaching experience is not rejected.

Analysis of Qualitative Data

The analysis of the qualitative data is presented in two parts. The first part presents the summary of the results of the Global Classroom Instructional Survey (GCLS). Despite its name, the GCLS is a checklist not a survey. It was determined early in the study that the checklist might provide the researcher with insights into how the seven teachers felt about teaching from a global perspective. Data from this checklist helped guide classroom observation and researcher reflections.

\section{Global Classroom Instructional Survey}

The survey, which had 15 items, shows how teachers in GOSSE and non-GOSSE programs compared in expressing understanding of the use of global concepts, themes, and appropriate strategies in the classroom. The questions in the survey were designed to find out whether the respondents were familiar with instructional strategies and whether they used multiple resources in the classroom.

One hundred percent of the respondents from the GOSSE program said "yes" to all the questions. Eighty percent of the teachers from the non-GOSSE program said "yes". This suggests that majority of social studies teachers in the study are aware of 
concepts, themes, and the appropriate strategies to use to teach global education. Only $30 \%$ of the teachers in the non-GOSSE program responded positively to the question:

"Do you use current events and the issues-centered approach when infusing global perspective in your classroom?" Seventy percent from the non-GOSSE group indicated no. One hundred percent of the teachers in the GOSSE program responded with a "yes" to the question.

The significant difference between the two groups suggests that teachers who had trained in teaching from a global perspective, the GOSSE group, use current events and the issues-centered approach more frequently than teachers in the non-GOSSE group in teaching global education. Two factors accounted for this difference. One factor is teacher preparation. Training in global pedagogy is necessary and critical to using it in one's teaching. The other factor is teachers' level of global knowledge and global mindedness. As Shulman (1978) has pointed out, teachers need to be grounded in both content knowledge and pedagogical content knowledge. Many global education researchers (e.g., Cruz, 1990; Kirkwood, 1995; Merryfield, 1997; Tucker, 1983; Zong, 1999) have shown the link between having knowledge and understanding of global theory and classroom practice that reflects this knowledge.

\section{Classroom Observations}

The second part presents the findings of the classroom observation. In this activity, the researcher was interested in using the Hanvey model to explore the relationship between teachers' global knowledge, global mindedness, and classroom practice. Seven social studies teachers, two of whom team-taught a class, were observed to determine whether global knowledge, global mindedness, and appropriate instructional 
strategies are manifested in their teaching of global education. Initially, there were three groups in the study, the GOSSE, non-GOSSE, and TWTOS. Because TWTOS consisted of teachers who teach non-social studies subjects, it was decided that they were not to be included in the classroom observation.

The following questions and criteria guided the analysis and interpretation of the classroom observation (Borich, 2003):

1. How are classroom chairs, desks and tables arranged? The idea here is how students are seated and positioned to discuss and debate current events or controversial issues, to tackle complex global problems and finding solutions, reflect the teacher's philosophy of education. I believe that the way the seats are arranged says much about how a teacher delivers instruction. A triangular, circular, or small round chairs formats suggest a teacher's pedagogical philosophy. In a social studies classroom, where the discussion of current or controversial issues is critical, students should be able to see who is making what argument.

2. How do teachers and students interact as they discuss current events, controversial issues, and global problems? Teacher to student and student to student interactions have been cited as factors impacting learning in the classroom (Kirkwood, 1995). Students' global mindedness is shaped when interactions within the classroom are purposeful and meaningful.

3. What are the modes of instruction? Examples of modes of instruction are: direct instruction, lecture, demonstration, group activity, textbook-oriented, teachercentered, student-centered, and project-oriented. 
4. What multiple resources do teachers use? Examples of multiple resources are: cable educational networks, radio (National Public Radio), the Internet, magazines, and newspapers.

5. Do teachers use different levels of questioning (Bloom's taxonomy)?

During the course of the classroom observations, the following indicators were observed:

1. The use of hands-on learning activities and instructional strategies including demonstrations, role-plays, simulations, discussions, and lesson plans.

2. The use of concepts and theories to explain how the concepts and themes of global and human interconnectedness and interdependence work.

3. The use of diversity (students, cultural plays, drama, guest speakers) from within or outside the classroom to explain global intricacies and complexities.

4. The use of teaching tools such as textbooks, newspaper, magazines, VCR, Internet, maps, and the cable networks such as FOX and CNN.

5. The use of a conceptual framework or model for teaching global education. The researcher continually reviewed the questions and criteria mentioned earlier and the previous global education frameworks designed by global education researchers in Miami-Dade County Public Schools (Cruz, 1990; Kirkwood, 1995; Zong 1999). Cruz, examined the effects of a globally oriented social studies program on the teaching behaviors of secondary level pre-service teachers. Kirkwood, in her study, observed social studies teachers who taught from a global perspective. Zong observed preservice social studies teachers who infused global perspectives in their lessons using the Internet. 
Research in global education indicates that students who are exposed to current and controversial issues develop a greater sense of global understanding and positive global attitudes (Cruz, 1990; Kirkwood, 1995; Merryfield \& White, 1996; Tucker, 1983; Zong, 1999). Therefore, improving teachers' global mindedness is critical if we want to improve students' cognitive, affective, and participatory skills (Diaz, Massialas, Xanthopoulas, 1999). Therefore, data concerning participant teachers' global mindedness was gathered from observations of them teaching and from repeated discussions with them.

The profile of the seven teachers from GOSSE and non-GOSSE programs is presented in Table 8 . The age, gender, ethnicity, degree, school, and subjects taught by each teacher are shown. The plus and minus signs indicate that a teacher has more or less than 10 years experience teaching social studies.

Two female and five male teachers were observed. Their ages range from the $30 \mathrm{~s}$ to the 50 s and they have between five and 20 years of social studies teaching experience. Over the years, the participants have taught social studies subjects such as American Government, American History, World History, Geography, Economics, Sociology, Psychology, and Global Studies. In the next section, the analysis of the classroom observations is presented. The analysis is descriptive. The description of the seven teachers and their schools is also provided. Direct quotes from field notes (where appropriate), are used to describe what was observed. The section is divided into four categories: infusing global perspectives, examples of classroom discussion, analysis of classroom activity, and reflection on classroom observation. 
Table 8

Profile of Social Studies Teachers Selected for Classroom Observation

\begin{tabular}{|c|c|c|c|c|c|c|}
\hline $\begin{array}{l}\text { Name/ } \\
\text { Group }\end{array}$ & Age & Gender & $\begin{array}{c}\text { Race/ } \\
\text { Ethnicity }\end{array}$ & School & Degree & Subject Taught \\
\hline $\begin{array}{l}\text { Mr. A } \\
\text { Non- } \\
\text { GOSSE }\end{array}$ & $50+$ & Male & Black & Coral Park & B.S. & $\begin{array}{l}\text { American } \\
\text { History }\end{array}$ \\
\hline $\begin{array}{l}\text { Ms. B } \\
\text { Non- } \\
\text { GOSSE }\end{array}$ & $50+$ & Female & White & $\begin{array}{l}\text { Design } \\
\text { School }\end{array}$ & M.S. & Economics \\
\hline $\begin{array}{l}\text { Mr. C\& } \\
\text { Mr. D } \\
G O S S E\end{array}$ & $\begin{array}{l}30- \\
40\end{array}$ & Male & Hispanic & Coral Park & B.S. & World History \\
\hline $\begin{array}{l}\text { Ms. E } \\
\text { Non- } \\
\text { GOSSE }\end{array}$ & $\begin{array}{l}40- \\
50\end{array}$ & Female & Black & Coral Park & B.S. & Economics \\
\hline $\begin{array}{l}\text { Mr. F } \\
G O S S E\end{array}$ & $\begin{array}{l}30- \\
40\end{array}$ & Male & Hispanic & South West & M.S. & Economics \\
\hline $\begin{array}{l}\text { Mr. G } \\
\text { Non- } \\
\text { GOSSE }\end{array}$ & $50+$ & Male & White & Braddock & Ed.D. & Economics \\
\hline
\end{tabular}

Hanvey Dimensions

The Hanvey (1976) model, which has been widely used by social studies teachers, was used as a framework that provided the researcher a compass to make sense of the activities in the classroom during each observation. According to Kirkwood (1995) teachers trained in a globally oriented program guided by the Hanvey global education framework address the five dimensions use a variety of resources to teach from a global 
perspective. She observed that (a) the activities to address awareness of perspective consciousness include discussion of multiple perspectives concerning ideas and issues; simulations on perceptions of different societal norms and practices; differentiation between prejudice and discrimination; values clarification; causes and consequences of stereotyping; and the importance of respecting others with different orientation.

Furthermore, Kirkwood (1995) observed that teachers used critical analyses of print and non-print resources, identification of global events, issues, and problems, and examination of the effects of world conditions to address state-of-the-planet awareness. Other examples of global activities to address cross-cultural awareness, awareness of global dynamics, and awareness of human choices include comparative study of different cultures; examination of cultural, economic, ecological, political, social, and technological interdependence among nations; and inquiry into the decisions and choices individuals, groups, and nations make to shape the world. Kirkwood provided examples of activities that typically address the five dimensions of the Hanvey model:

Hanvey dimension 1. Activities include discussion of multiple perspectives concerning ideas and issues; simulations on perceptions of different societal norms and practices; differentiation between prejudice and discrimination; values clarification; causes and consequences of stereotyping and scapegoating; and the importance of respecting others with different orientations (Cruz, 1990; Kirkwood, 1995; Zong, 1999).

Hanvey dimension 2. Activities include critical analysis of print and non-print resources; identification of global issues and their impact; examination of the effects of world conditions on students lives and community; and mapping of cultural, physical, and interdependent regional characteristics (Cruz, 1990; Kirkwood, 1995; Zong, 1999). 
Hanvey dimension 3. Activities include a comparative study of cultures; roleplaying and storytelling; inquiry into cultural borrowing, cultural diffusion and their effects on people and nations; emphasis on the commonalities rather differences of cultures; and development of tolerance and empathy (Cruz, 1990; Kirkwood, 1995; Zong, 1999).

Hanvey dimension 4. Activities include strategies that demonstrate systemsthinking; cultural, economic, ecological, political, social, and technological interdependence among nations; and identification of reciprocal linkages of people and nations to local communities (Cruz, 1990; Kirkwood, 1995; Zong, 1999).

Hanvey dimension 5. Activities include inquiry into the choices individuals, groups, and nations make that influence the future of the world; identifying, planning, and implementing a community project of local and global implications; and connecting electronically with peers worldwide to share concerns and propose solutions to global problems (Cruz, 1990; Kirkwood, 1995; Zong, 1999).

\section{Social Studies Teachers in the Classroom}

Social studies teachers have the primary responsibility of raising awareness of global issues, problems, and events in the classroom. Therefore, for secondary social studies teachers the challenge lies in helping their students improve their global knowledge and global mindedness. In the next section, the analysis of the seven social studies teachers is presented.

Teacher 1: Mr. A

Mr. A was observed teaching $12^{\text {th }}$ grade American History at Coral Park High School. He was selected from the non-GOSSE training program group. Coral Park High 
School is located in a predominantly Hispanic neighborhood. According to the MiamiDade County School District demographic data (2001), the school has 15 social studies teachers and an average class size of 28.7. Mr. A indicated on the survey that he received his bachelor's degree in social studies education in another other institution. He has been a social studies department chair and has over 25 years of classroom teaching experience. Mr. A also indicated that teaching at the school offer him the opportunity to make a difference in students' lives.

Mr. A was first observed on February 5, 2003. He was friendly and enthusiastic. His classroom is located in the East wing of the school, where all social studies courses are offered. His class size averaged $35\left(12^{\text {th }}\right.$ grade $)$ students, most of whom were Hispanic and female. The seating arrangement was traditional, a $6 \times 7$ row of chairs facing the blackboard. There was one computer with Internet access, an LCD panel, and a VCR and several U.S. and world maps in the classroom. Although Mr. A had been trained in a non-GOSSE program, in the classroom there appeared to be resources that would facilitate the infusion of and teaching from a global perspective. Mr. A was aware that his unit on American History would be measured against the criteria mentioned earlier and as to whether he infused or taught from a global perspective. Mr. A said he supports the infusion approach (Diaz et al., 1999) because it allows a teacher to teach global events, issues, and problems as they occur.

In the classroom, Mr. A had his chair and desk positioned behind his students. $\mathrm{He}$ said that this was done to have a better view of the classroom. During the first observation, after a period of explanation and demonstration, Mr. A took his seat as students worked on their assignments. Students were not put into groups; they were 
working independently. During follow-up visits to the class, the same instructional pattern was observed.

Infusing global perspectives. One day Mr. A's class had just begun a unit on African history, as part of the American History curriculum. One of objectives of the lesson was to broaden students' understanding of the complexity of events and issues in Africa. During our pre-observation meeting, Mr. A indicated to me, and later to his students, that he had not traveled to Africa and that all his travels had been done locally. He said his knowledge of Africa and the world came from listening to the National Public Radio (NPR), from watching the FOX and CNN cable networks, and from reading the Financial Times, the New York Times, and the Washington Post newspaper (Mr. A, personal communication, February 5, 2003). Based on what he had learned from these sources, in this lesson Mr. A applied a multidimensional approach and had students watch and critique a Fox news clip of events in Africa.

Examples of classroom global discussion. As Mr. A completed the unit on African history, his lesson plans indicated that he wanted to review and offer feedback on various projects during the week. The instructional goal for this unit was to introduce and expose students to the historical, cultural, economic, and political events in Africa. Other goals were aimed at introducing the concepts of global diversity, cooperation, harmony, understanding, and partnership. Mr. A's lesson plan read:

The student, after a questioning session on the goals and objectives of the African Union [AU], will determine whether African nations should make a strong commitment to solving the continent's serious economic and political problems, and whether the AU will play a significant role in global politics. 
During the lesson he used an open-ended strategy to engage his students in a dialogue about Africa with the intention of reinforcing global concepts such as interconnectedness, culture, interdependence, change, diversity and stressing the "local and global connections." Specifically, Mr. A said:

Today, we begin a unit on Africa. In the next few days, and throughout the month of February, we will focus on the continent of Africa: its peoples, cultures, politics, and problems. We will cover Africa thoroughly so that at the end of the month, each of you will learn and become aware of problems facing the continent, and perhaps learn how to resolve the ethnic conflicts. In addition, you will learn how African leaders make economic and political decisions" (FN: 02/05/03).

The class ended with a reflective activity. Mr. A asked his students to first identify the continent on the map and to sketch any country and/or create a map to demonstrate their knowledge of geography and history of the regions in Africa. An example of the class dialogue follows. Mr. A said:

Africa appears to be a continent in perpetual crisis. I want you to know that Africa is also a continent with a lot of potential. Africa remains the hub of human civilization. With its abundant human and natural resources, leadership and governance remain a major impediment to development. With the formation of the African Union, it is hoped that some of the lingering problems would be resolved. (FN: 02/05/03)

A student then asked, "Why do we need to learn about Africa, when Africa is so far away? And I don't understand why anyone would want to learn about these people and their tribes?" Mr. A responded by saying, "Very good question. Instead of me giving you my opinion, let's hear from your classmates." Another student said: "Africa is the largest continent with over 700 million people." The student then asked: "Do you know about the history of black people in America? Do you know about slavery?" Mr. A responded, "For that I am going to assign further readings on Africa and we will debate the issues tomorrow." 
Analysis of classroom activity. According to Taylor (1998) teachers will find strategies such as simulations, role-playing, and comparative studies helpful to students in understanding global events, issues, and problems. After providing an explanation and facilitating a discussion, Mr. A divided the class into four research groups. He gave each group a handout. Group One had researched the general history of the people of Nigeria, Ghana, Senegal, and Cote de Voire. Group Two investigated the political history of these West African nations. Group Three researched the history of South Africa, Botswana, Uganda, and Kenya. Group Four explored regional and global political and economic linkages. Several instructional strategies were evident: lecture, case study, cooperative learning, role-playing, and questioning. Mr. A expected his students to offer defensible and intellectually well-grounded answers to questions about Africa.

By focusing on the economic and political issues and problems in Africa, Mr. A skillfully infused current events in Nigeria, Sierra-Leone, South Africa, Uganda, Botswana, Senegal, and Cote de Voire, linking them to other parts of the world, particularly to Europe and America. He wanted his students to understand the struggle for independence and to appreciate the contributions African leaders like Nyerere, Azikwe, Lumumba, Mugabe, Nkrumah, and Mandela have made to Africa. After students presented their short research projects, he asked some questions so that they would examine how political and economic decisions are made in Africa.

Link to Hanvey model. Dimension 2 was evidenced in Mr. A's unit on Africa. Mr. A began by indicating to his students that he had not traveled to Africa and that all his travels had been done locally. An example of Dimension 2 can also be seen as students identified the continent of Africa on the map. In this dimension, students 
exemplified knowledge of the state-of-the-planet awareness using geographic knowledge. In their responses to questions and in their project presentations students were observed showing how decisions made in a region of Africa might affect people and the environment elsewhere. According to Barker (1991), geographic knowledge provides young people with perspectives, information, concepts and skills essential to understanding themselves, their relationship to the earth, and their interdependence with other peoples of the world.

Reflection on classroom observations. Mr. A was teaching a unit on Africa, which lasted several weeks. Although Mr. A seemed sensitive, thoughtful, and concerned about the issues in Africa, he failed to adequately make the global (big picture) connections. He provided opportunities for his students to examine the multiple perspectives held by different people about politics and political organizations in Africa and their relationship with rest of the world. However, students appeared not to be interested. This was evident in their group discussions, questions, and debates.

A variety of resources such as maps, a VCR, audio and videotapes, interactive online lessons from the Internet were readily available but were not used. In discussion, Mr. A acknowledged that students, at different times, have had access to these tools. Mr. A explained to me that a culminating activity for the unit was a simulation of a meeting of the African Union leaders, who had gathered for the African Summit to develop a new vision for Africa. Students argued and took different positions and developed position statements for each of the 53 nations in Africa. Students compared the choices and sacrifices early African leaders such as Nyerere, Azikwe, Lumumba, Mugabe, Nkrumah, Kenyatta, and Mandela made for independence in Africa with those made by other 
freedom fighters or revolutionaries around the world (Mr. A, personal communication, February 5, 2003).

In summary, based on classroom observations, repeated conversations with the teacher, and reflection on what instructional strategies were used, the researcher concluded that Mr. A (a) demonstrated knowledge of global events, issues, and problems, (b) used appropriate, but limited instructional strategies and (c) encouraged students to express multiple view points as they compared and contrasted global information. Teacher 2: Ms. B

Teacher 2 was also selected from the non-GOSSE training program group. The researcher met with Ms. B in her classroom in the morning. She appeared confident and enthusiastic. She was in her late forties and a National Board certified teacher. She was observed teaching Advanced Economics to $12^{\text {th }}$ grade students at the Design and Architecture Senior High School. According to the Miami-Dade County School District demographic data (2003), the Design and Architecture Senior High School had an average class size of 20.8 , with three social studies teachers. The school is located in downtown Miami in an area called "Design City." Her school, the Design and Architecture Senior High offers a college preparatory program, which includes standard, honors, and advanced placement courses. The school is recognized by the United States Department of Education as a Blue Ribbon School, and a model for the School-to-Work Initiative. The student body is comprised of Hispanic, White, Black, and other ethnic groups with a student population of about 500 . The social studies program offers World History, American History, Government, and Economics. 
On the wall in Ms. B's classroom were visuals such as pictures and posters of famous economists and world political leaders who have shaped and reshaped the world, suggesting a teacher committed to global studies. She had magazines and newspapers readily available to students. Students walked in at the beginning of class picked up a newspaper and began to identify newsworthy local and global issues. In addition, there were auditory materials such as a radio, a tape recorder, a VCR, and computers.

Infusing global perspectives. On my second visit on February 14, 2003, I visited from 7:30 to 9:30 a.m. Ms. B's instructional goals were to increase students' knowledge of the world, develop their problem-solving and reflective skills, and raise their awareness of and interest in debating controversial issues. She also wanted her students to do well and pass the Advanced Placement examinations at the end of the school year. She was once a district "teacher of the year" for Miami-Dade County. On this day, February 14, the lesson was on the "Presidential Decision: North Korea and Iraq." Four reflective questions were on the chalkboard. As students took their seats, they each picked up a newspaper and began reading. Teaching for global understanding requires students to gather information from many sources (Kirkwood, 1995). On the blackboard were some prompts for the students concerning cloning, military draft, the United Nations and weapons inspections in Iraq and North Korea.

Examples of classroom discussions. Ms. B's approach and style of teaching about the world was unique. There were about 25 students present during this visit. This small class size allowed her to develop a one-on-one relationship with students. Students sat in groups of five at tables facing one another. The class discussion began after students signaled that they were ready, suggesting that students typically initiated the class 
discussion. The discussion began when one of the students voiced her displeasure about America's involvement in Iraq. She lamented: “America has no business in Iraq. It is all economic!" Ms. B allowed the student to fully express her opinion on the matter. She explained to the class that each individual has a view of the world that must be respected, that this view of the world shapes how we view others. Moreover, she stressed that others have views of events in the world that are profoundly different from one's own.

Furthermore, staying on the same topic, Ms. B made the point that American involvement had both material and non-material benefits. Although the material benefits may outweigh other benefits, it is important for America to be involved in that part of the world. She said President George W. Bush declared Iraq, Iran and North Korea the "Axis of Evil" in his January 2002 State of the Union address because these nations are directly or indirectly involved in international terrorism and in the proliferation of weapons of mass destruction. Moreover, she said, the Korean Peninsula is of grave interest to America. The Persian Gulf region is economically and militarily significant to the United States. American economic and military interests must be secured in the region.

Analysis of classroom activity. On March 24, I visited Ms. B's second period Advanced Economics class. Out of the 25 students, more than half of them were female. As students approached their seats, they each picked up the Miami Herald newspaper, a Miami local paper. As students skimmed through the pages of the newspaper, Ms. B was busy taking attendance and observing how students selected topics of interest. She allotted 10 to 15 minutes to silent reading. I observed that students generated the questions for discussion while Ms. B listened and moderated the discussion. She ended this lesson by asking her students to briefly summarize the main ideas in the newspaper. 
Culminating activities were simulation and role-playing activities. For the first lesson, students had an open-ended discussion about implications of U.S. foreign policy. In the second lesson, students were issued Ms. B's dollars to trade and bargain on Wall Street. For example, in her lesson on multinational corporations, Ms. B asked her students to research the Fortune 500 magazine for class presentation. The Fortune 500 magazine chronicles the top 500 largest multinational corporations and publishes their impact on the world economy.

Link to Hanvey model. Dimensions 1, 2, 4, and 5 were evident in Ms. B's lessons, Presidential Decision: North Korea and Iraq. Ms. B had four guiding questions on the board for class discussion. The questions and their connections to the model follow.

1. Now that the ability to clone is well within our grasp, how do you feel about the uses of it? This question addresses teachers' global knowledge and global mindedness as indicated on the global mindedness scale that measures attitudes about global responsibility, cultural diversity, global centrism, and interconnectedness (Hanvey, 1976; Dimension 1)

2. Should the draft be mandatory? This question addresses local, national, and global implications and the concept Think globally and act locally. Students discussed how military drafts are conducted in other nations compared to how it is done in the United States (Hanvey, 1976; Dimensions $3 \& 4$ ).

3. How well has the United Nations (UN) conducted the weapons inspection in Iraq? The UN is the world governing body created after World War II to provide global security. The UN's involvement in Iraq is a global event. Students explored the pros and cons (Hanvey, 1976; Dimensions 3 \& 4). 
4. How do you think the situation in North Korea should be handled? Students compared and contrasted, and gave their opinion as to how the situation should be handled (Hanvey, Dimensions 3, 4 \& 5).

Ms. B had a discussion about how each individual has a view of the world that must be respected, and that this view of the world shapes how we view others (Hanvey, 1976; Dimension 1). Furthermore, President George W. Bush's declaration that Iraq, Iran, and North Korea make up an Axis of Evil generated a lot of class discussion. Students explored the concept of international terrorism and the proliferation of weapons of mass destruction. Ms. B explained and clarified as the students discussed the impact of international terrorism and weapons of mass destruction.

Reflection on classroom observations. Ms. B appeared to have global knowledge and pedagogical knowledge for teaching global education. She appeared to be comfortable in teaching with a global perspective and in applying issues-centered instructional strategies. She moved around the room helping students individually and in groups. She also allowed her students to select topics of interest from the magazine and newspaper. She did not teach from the textbook. She provided a historical context and stressed the building of perspective consciousness (Hanvey, 1976). During one of the post observation discussions with the researcher, she said developing skills in perspectives consciousness would help students recognize, examine, evaluate, and appreciate multiple perspectives on particular issues, a conflict, or a concern.

The dominant mode of instruction in Ms. B's classroom was a combination of student-centered and direct instruction. It was obvious in her dialogue with her students that Ms. B was urging students to recognize the difference between social justice and 
injustice as she discussed an article on the oil situation in Nigeria. She also allowed students to move freely without interference or disturbance. For example, during one of the observations, a student walked up to the teacher's desk, picked up a hall pass and excused himself to the bathroom without disrupting the lesson, and returned within five minutes (FN: 03/24/03; Ms. B, personal communication, March 24, 2003).

In summary, based on the classroom observations, repeated conversations with the teacher, and researcher reflection on instructional strategies used to teach from a global perspective, the researcher concluded that Ms. B (a) demonstrated knowledge and understanding of global events, issues, and problems, (b) used appropriate instructional strategies, and (c) encouraged students to express multiple view points, and compare and contrast global information. Examples of instructional strategies used by Ms B include simulations, demonstration, group activity, discussion, probing, and questioning. Teachers 3 and 4: Mr. C and Mr. D

Teachers Mr. C and Mr. D are in their mid-30s. They team-taught in the auditorium at Coral Park High School. They were selected from the group that attended a GOSSE program. Both are graduates of the FIU College of Education social studies education program. They taught $11^{\text {th }}$ grade World History to about 100 students. The auditorium was filled with history textbooks. There were instructional materials such as maps, an overhead projector, a monitor, and a VCR. Mr. C was a former U.S. Marine and Mr. D told the researcher that he enjoyed teaching sociology and philosophy. Mr. C was the disciplinarian of the team. The team teaching arrangement provided them both with the opportunity to collaborate and develop interdisciplinary lesson plans. 
Infusing global perspectives. On the day they were observed, students were preparing for the mid-term examination coming up the following week. The class was divided into several small groups. Each group had about six students. They were to respond to (a) the similarities and differences between the $1^{\text {st }}$ and $2^{\text {nd }}$ Gulf wars, (b) reasons why America is in Iraq, and (c) the role of the United Nations in post-war Iraq. Group 1 represented the viewpoints of the Iraqi people. Students had been told to research and report their findings to the class. As they worked, the group leader said, "I think we should describe why America is invading Iraq first." Another student said, "Let's talk about the impact on family life after the war."

Meanwhile, Group 2 was brainstorming viewpoints from other geographic locations. This group was discussing and exploring the questions they would pose to the other groups about their perception of the war in Iraq. Simultaneously, Group 3 was busy creating and constructing ideas about post-war Iraq. After the groups completed their group discussions and presented their reports to the class, they were told to prepare for a class debate on the impact of the war on the region and the world. After the debate, Mr. $\mathrm{C}$ and Mr. D clarified the points that had been presented and brought the lesson to a closure. The simulation strategy was used. Students participated in a simulation of the $2^{\text {nd }}$ Gulf War by demonstrating and simulating the dangers of weapons of mass destruction and its implications through a "man of war" activity designed by Mr. C. Students were then asked to write an essay, speculating about the causes and effects of war.

Analysis of classroom activity. Data analyses show that in their unit on the War in Iraq Mr. C and Mr. D demonstrated global knowledge and skills by infusing global 
perspectives. All the five Hanvey global education dimensions were evident: (a) perspective consciousness - students were observed examining their beliefs and values, (b) state-of-the-planet awareness - students were discussing the impact of the war on the planet, (c) knowledge of global dynamics - students were discussing the global implications, (d) cross-cultural awareness - students were discussing the different cultures affected by the war and (e) awareness of human choices - students were discussing the decisions and choices leaders on the battlefield have to make that may impact the lives of soldiers defending their countries.

Furthermore, the teachers were asking students to imagine their country being attacked by another country (perspective consciousness), students were asked to imagine the decisions and choices leaders have to make, and students were discussing and debating the political, economic, and cultural impacts of the $1^{\text {st }}$ and $2^{\text {nd }}$ Gulf wars. It was clear that both teachers continually referred to past and current events, making linkages, and stressing interdependence and interconnectedness of systems and cultures.

For example: On March 26, 2003, Mr. C and Mr. D began the class by asking their students to take their seats, and as they did that, they wrote a sentence or two about their views on the war in Iraq. To help the students comprehend the assignment, they posed a question asking students to imagine how they would feel if they were asked to fight for their country in order to defend and spread democracy. Students were observed consulting with one another on how best to respond to the assignment.

Speaking from experience, $\mathrm{Mr}$. C reminded the class that one of the valuable reasons to study the causes of conflicts is to understand what has happened in the past that caused the conflict and the potential for conflict resolution in the future. By 
understanding the global community and the social climate in which we find ourselves today, sometimes knowing what goes on around the world may help us make informed and better decisions about other people and their cultures.

Link to Hanvey model. Dimensions 1, 2, 4 and 5 were evident in this global lesson. The GOSSE teachers posed a question to their students: "How would you feel if you were asked to fight for your country in order to defend and spread democracy around the world?" It also addressed these teachers' global knowledge and global mindedness in the classroom. For example, these two teachers explained to their students that "two world wars killed over 60 million people and ruined the lives of many others. Conflicts have long last effect on people." Students were seen discussing the nature of conflicts and the role of the U.S. in establishing global security. Some of the students' comments expressed the idea that most governments pursue their national security interest. Most of the students said they would fight for the country if asked to do so; whether to promote democracy around the world or protect the nation from external aggression. Students expressed different viewpoints about the world [expressing feelings, global mindedness].

Examples of Dimension 2, 4, and 5 were seen when students were discussing the choices and decisions made on the battlefield by the commanders, and how lives are changed forever by those decisions. Example of a global mindedness activity included students imagining September 11, 2001 attacks happening again. The instructional strategies used by teachers $\mathrm{Mr}$. C and Mr. D are appropriate to teaching these dimensions. For example, Mr. C shared his personal experience in a combat as a marine in the form of storytelling. He emphasized duty to the nation and taking responsibility. 
Reflection on instructional strategies. To teach a global lesson in an auditorium with over 100 students is challenging and difficult. A case study was used to help students see how understanding the bigger picture can help them make better decisions. The teachers allowed students to read from the textbook and then asked questions to check students' comprehension of the causes of the war in Iraq. The instruction was a mixture of student-centered, teacher-centered, and textbook-centered. After students presented their research to the class, the teachers asked questions so that students would examine long-term implications of the war. The culminating activity was the students' oral presentation of their research to the rest of the class. (Mr. C \& Mr. D, personal communications, March 26, 2003).

In summary, based on the classroom observation, conversations with the teachers and reflections on instructional strategies used, the researcher concluded that $\mathrm{Mr}$. C and Mr. D (a) demonstrated knowledge and understanding of global events, issues, and problems, (b) used appropriate instructional strategies. Examples of instructional strategies used by Mr. C and D included lecture, group activity, and questioning. Teacher 5: Ms. E

Ms. E teaches $12^{\text {th }}$ grade Economics classes at Coral Park High School. She has taught social studies courses for over 30 years. She was selected from the non-GOSSE training program group. She is a serious and well-respected teacher. The following instructional tools were visible in the classroom: a computer with Internet access, an LCD panel, a VCR, newspapers, and magazines (New York Times, USA Today, Financial Times, Newsweek), and United States and World maps. 
Infusing global perspectives. Ms. E believed in the infusion approach to teaching from a global perspective. This belief was reflected in her lesson plans and in her style of teaching. Ms. E provided opportunities for her students to examine economic and political issues from multiple perspectives, critically examining the viewpoints held by leaders from other nations, economists, and politicians about issues of national and global significance. Further, Ms. E infused local events to teach from a global perspective such as local business having ties with the Caribbean and Latin America. The instructional strategies for teaching from a global perspective were: simulation, role-playing, lecture, and demonstration.

Examples of global dialogue. Ms. E was beginning a unit on the world economy. Teaching about the aggregated world economy from a global perspective is a big undertaking. Therefore, Ms. E decided to narrow the scope by examining how socialist and capitalist economies have changed the world. Concepts such as dependency theory, interdependence, and interconnectedness of systems were included in a global classroom discussion observed. Students highlighted the similarities and differences between the two economies. Her Honors and Advanced Placement classes were up to the task. The students appeared composed and ready to discuss global issues. They were well behaved. Students worked from their worksheets and textbooks, while Ms. E sat quietly as they worked. Students sat quietly in rows with little interactions between them and the teacher.

Analysis of classroom activity. The classroom activity was traditional and textbook-based. Analyses of classroom activities show that Ms. E interacted very little with her students. As students walked into class, they had their economics textbooks 
with them. Some picked up an Economist magazine and started reading before the lesson began. The lesson consisted of students working from a worksheet and the textbook. The teacher went over questions in the textbook. Students were asked to complete their research on the world economy and be prepared to make oral presentations to the class. There was no culmination activity. Emphasis seemed to be placed on mastery of content. As students were doing their activity, the bell rang. Students then dropped off their work in a basket.

Link to Hanvey model. Dimension 4 was evident in Ms. E's lesson on the world economy. Students were seen comparing and contrasting the different economic systems around the world, and how these economic systems (capitalism and socialism) are affecting progress and development in some developing nations. According to Kirkwood (1995), dimension 4 requires teachers to teach students to understand the systemic and interdependent nature of events and issues.

Reflection on instructional strategies. Instructional strategies were limited. Ms. E did not use explanations, demonstrations, or issues-centered strategies. She did not vary her instructional strategies. Students simply worked from the textbook. Although Ms. E had all the instructional tools in her classroom, she did not use them to teach from a global perspective. The lesson was not only textbook-oriented, it was teacher-oriented. The LCD projectors, textbooks, and VCR were visible, but remained unused. In summary, based on classroom observations, conversations, and reflection on instructional strategies used, the researcher concluded that Ms. E (a) demonstrated limited knowledge and limited understanding of global affairs, (b) used limited instructional strategies and (c) failed to encourage students to express multiple view 
points, or to compare and contrast global information. Examples of instructional

strategies used by Ms E include explanation and student worksheets.

Teacher 6: Mr. F

Mr. F was selected from the GOSSE training group. He taught $12^{\text {th }}$ grade regular Economics. He has taught social studies for 10 years at Southwest Senior High School. The majority of the students attending this school are Hispanic. The following instructional tools were visible in the classroom: a computer with Internet access, an LCD panel, a VCR, newspapers, magazines, and United States and world maps.

Infusing global perspectives. Mr. F believed in the infusion approach to teaching from a global perspective. His lesson plans showed activities that indicated a focus on teaching global interdependence. Students were observed engaged in these activities.

Examples of global dialogue. In one class the researcher observed, Mr. F began a unit on the impact of globalization around the world by referring students to the world map, where he pointed to Europe and referred to it as the seat of early industrialization and trade. Trade is the source of globalization, which has become a phenomenon that is changing the world. The goal was to develop awareness in students of concepts such as interdependence and interconnectedness of systems and their impact on the world economy. His class was composed of well-behaved, high performing students, with a few who are low performing and below average academically. Teacher F introduced the topic and students started working on case studies from the textbook.

Analysis of classroom activity. Data analyses show that in his unit on the impact of globalization, Mr. F demonstrated global knowledge and skills in infusing global perspectives. Students got into groups of five to discuss and debate the impact of 
globalization on developing nations. Each group had a theme and a region: Group 1 had Africa; Group 2, Latin America; Group 3, Europe; Group 4, Asia, and Group 5 the Caribbean. Students were instructed to research a country in their region that was the most impacted by globalization. The groups chose Botswana, Chile, Belgium, Malaysia, and Jamaica. Teacher F's lesson plan showed that he intended to infuse the five Hanvey global education dimensions: perspective consciousness, state of the planet awareness, cross-cultural awareness, knowledge of global dynamics, and awareness of human choices (Hanvey, 1976) into his lesson. For example, students were discussing how global competition and trade would impact the selected countries.

Link to Hanvey model. Dimension 4 was evident in Mr. F's unit on the impact of globalization on developing nations. He explained to the students that globalization is a complex concept to teach as it means different things to different people. Globalization has negative and positive aspects. For example, globalization has resulted in the establishing of multinational enterprises operated from the industrialized countries for their own profits; often this is detrimental to the standard of living of people in the developing nations. Similarly, globalization has opened national boundaries and brought enough wealth to some nations.

Reflection on instructional strategies. The dominant instructional strategy was cooperative learning. Mr. F used a variety of resources. Students were seen moving around discussing various aspects of globalization and the world economy. There was instruction going on, as the teacher was seen moving listening in on the discussion, and offering comments and clarifications. The instruction was student-centered, as students were seen using the LCD projectors, textbooks, or the VCR during their group 
presentations. The teacher walked around the class correcting, explaining, and clarifying ideas and concepts. Students presented the pros and cons on globalization in each country. For example, students debated the merits and demerits of globalization, focusing on the protests in Europe and America. They also made recommendations to developing nations suggesting how globalization could stimulate development. Mr. F used current issues to teach from a global perspective (Mr. F, personal communication, March 28, 2003).

In summary, based on classroom observations, conversations with the teacher, and reflection on instructional strategies used, the researcher concluded that Mr. F (a) demonstrated knowledge and understanding of global events, issues, and problems, (b) used appropriate instructional strategies and (c) encouraged students to express multiple view points, and to compare and contrast global information. Examples of instructional strategies used by Mr. F include group activity, discussion, demonstration, and questioning. Teacher 7: Mr. G

Mr. G is a social studies teacher at Braddock High School. The student body at this large school is very ethnically/racially diverse. Mr. G has taught social studies for over 35 years. At the time of the study he was teaching $12^{\text {th }}$ grade American Government and Economics. He was selected from the non-GOSSE trained group. There were about 30 students in his class. Computers with Internet access, an LCD panel, a VCR, and United States and world maps were visible in the classroom.

Infusing global perspectives. Mr. G's unit was on world economic systems and institutions geared towards understanding how the following systems and agencies are 
linked: World Bank (WB), International Monetary Fund (IMF), World Trade

Organization (WTO), United Nations (UN) and World Health Organization (WHO). Mr. $\mathrm{G}$ indicated that these systems, institutions, and agencies provide an opportunity to show how global interdependence and interconnectedness work.

Examples of global dialogue. Mr. G introduced the unit on global systems and institutions to his students by referring them to various magazines articles and the textbook. Students were asked to research each agency, institution, and organization before coming to class. Students worked from their notebook and from worksheets in the textbook; they worked individually and in groups. They were to study their notes for the first hour. The class presentation began in the second hour.

Analysis of classroom activity. Students were seen at first seated in their individual seats in rows working from their textbooks. Later, they got into three main groups: a UN Group, a WTO Group, and a IMF/WB Group. Each group presented their research based on the findings. For each group, students examined mission statements and goals, hiring practices, diversity, contributions, and global impact. Instructional strategies varied: role-play, case study, demonstration, explanation, and simulation. The classroom atmosphere was both teacher- and student-centered.

Link to Hanvey model. According to Kirkwood, (1995), students need to develop an understanding of how globalization as a system comprises of cultural, ecological, economic, political, and technological dimensions. Dimension 4 was evident in Mr. G's lesson on economic globalization. Stressing global interdependence and interconnectedness, Mr. G explained to his students that the problems facing the human race today are global problems. Economic globalization is creating new global realities, 
he said. Many observers of globalization have concluded that globalization has positive and negative aspects. Critics of globalization continue to argue that globalization is widening the gap between the rich and poor nations. Students were seen discussing the evolution of these international agencies and institutions such as WB, IMF, WTO, WHO, and United Nation Educational, Social and Cultural Organization (UNESCO) and their role in globalizing the world. For example, students were seen presenting a research to the class on the role of UNESCO in developing nations. Examples of observed strategies used for this lesson include lecture and a cooperative learning activity.

Reflection on instructional strategies. The strategies used were a mixture of individual and cooperative learning. Mr. G used a variety of resources such as textbook, magazine articles and students' notes. Students were seen moving around the class and appeared focused and on-task. The teacher was also observed moving from one station to the next listening and offering feedback, comments and clarifications. Students used the LCD projectors, textbooks, or the VCR, as they deemed appropriate. (Mr. G, personal communication, April 11, 2003). Examples of instructional strategies Mr. G was observed using included lecture and questioning.

In summary, based on classroom observation, conversations with the teacher, and reflection on instructional strategies used, the researcher concluded that Mr. G (a) demonstrated knowledge and understanding of global events, issues, and problems, (b) used appropriate instructional strategies and (c) encouraged students to express multiple view points, and to compare and contrast global information. Examples of instructional strategies used by Ms. G include demonstrations, group activity, discussions, presentations, worksheets, textbooks, and student notebooks. 
In Table 7, the comparison of teachers from GOSSE and non-GOSSE training programs on how they applied global knowledge, global mindedness, and instructional strategies in the classroom is presented. The purpose of the classroom observations was to determine the instructional strategies the selected social studies teachers used to teach from a global perspective. The guiding research question was: Do teachers from the GOSSE training group infuse global perspectives into the curriculum differently than teachers from the non-GOSSE training groups?

Similarities. The data show that teachers from GOSSE and non-GOSSE groups alike infused and taught from a global perspective. No major difference was found in their levels of infusing global perspectives in their classroom instruction. It should be noted that the textbooks they all used had a "Global Connection Unit" at the end of each chapter. It is accessible and easy to reference. The data also show that the lesson plans had multiple instructional strategies, which were checked off by all the teachers. This is in compliance with $\mathrm{CBC}$ requirements. Multiple instructional resources and teaching tools were visible, which were used at various intervals.

Differences. A difference was found in the appearance of a conceptual framework or a model to teach global education. The Hanvey (1976) global education framework could be discerned underlying the lessons taught by teachers in the GOSSE group.

Overall, within and between groups, there were minor differences in how global knowledge and global mindedness were taught. For example, there was no evidence that teachers in either group emphasized global mindedness. The Hanvey model encourages the teaching of global mindedness. Only Ms. B, Mr. C, and Mr. D asked students about 
Table 9

Similarities and Differences in Modes of Instruction and Teaching Strategies

Teacher/Group $\quad$ Modes of Instruction Teaching Strategies

Teacher 1: Mr. A

Non-GOSSE

Teacher 2: Ms. B

Non-GOSSE

Teachers 3 and 4 :

Mr. C and Mr. D

GOSSE

Teacher 5: Ms. E

Non-GOSSE

Teacher 6: Mr. F

GOSSE

Teacher 7: Ms. G

Non -GOSSE textbook oriented, teacher-

centered

textbook oriented, student-

centered

Direct instruction, textbook oriented, teacher-centered

Textbook and teachercentered.

textbook, student-centered, project-oriented
Lecture, group work, discussion, questioning, multiple resources

Lecture, cooperative learning, questioning, probing, multiple resources

Lecture, group work, questioning, Hanvey model

Lecture and explanation

Demonstration, group work, questioning, multiple resources, Hanvey model

textbook, teacher-centered, Lecture, group work, project-oriented questioning.

their feelings on personal and social issues, and how their feelings are expressed to change their worldview. There were differences in teaching styles and in the choice of strategies to use. This is expected because teachers teach differently. No two teachers teach the same way. Individually, Ms. B, Ms. E, and Mr. F, who all taught economics, were concerned about students' understanding of economic concepts. They focused their instruction on economic themes such as economic choices, decision-making, opportunity costs, and economic interdependence and intercultural interconnectedness. 
The data also show that teachers differ in how they write up their lesson plans. Some lesson plans were more detailed than others. Teachers also differed as to whether or not they infused current or controversial events. Global educators find incorporating current events is essential in a social studies classroom because it will encourage students to discuss and argue controversial issues without fear. Mr. A, Ms. B, Mr. C, Mr. D, and Ms. G infused current events consistently in their lessons. Only Ms. B was observed challenging her students to think at higher cognitive and affective levels, which she did throughout the observed lessons.

In Ms. B's class, students were encouraged to compare and contrast such things as multinational corporations, roles of CEOs, and the role of governments in different nations. In examining rules, regulations, and cultural norms in various countries, students gain insights into various perspectives and begin to perceive that others see and view the world differently. Students also examined current events, used maps to locate places and linked currencies to countries around the world. Furthermore, Ms. B taught her students to speculate about the economic future of the world through cross-cultural simulation activities [cross-cultural awareness]. She stressed that to preserve our global economic future, students must first understand that resources are finite.

Ms. B also emphasized the concept of "think globally and act locally" as she involved her students in various activities. For example, the discussion of the events and the loss of lives in the oil-producing region of Nigeria was a case in point. Students were asked to imagine living in that part of the world. Finally, an attempt was made to make the local to global connection in the examination of homelessness, hunger, poverty, and violence in the community the students reside in (Hanvey, 1976). 


\section{Summary}

In this chapter, the data of the study were analyzed and the findings were presented. Four hypotheses were tested. The analysis of the quantitative data showed that teachers from a globally oriented social studies program were significantly different in their global knowledge than teachers from non-GOSSE and TWTOS groups.

The analysis of the qualitative data showed that the Hanvey model was discerned only in the GOSSE trained teachers' lessons. For both the GOSSE and non-GOSSE trained teachers, multiple instructional strategies were observed, especially issuescentered approaches, simulations, role-playing, and demonstrations. In the next chapter, the discussion of the results of this study will be related to the literature and recommendations will be offered. 


\section{CHAPTER V \\ DISCUSSION}

This chapter presents an overview of the study, a summary of the findings, discussion of findings, conclusions, implications, and recommendations.

\section{Overview of the Study}

The purpose of this study was to examine the factors that contributed to teachers' global knowledge, global mindedness, and pedagogy in global education. The participants were secondary level teachers with the Miami-Dade County School District in Florida. Ninety teachers were randomly selected and placed in three groups. Group 1 consisted of social studies teachers from a globally oriented social studies teacher education program (GOSSE). Group 2 was comprised of social studies teachers who were not from a globally oriented social studies teacher education program (nonGOSSE). Group 3 consisted of teachers who do not teach subjects other than social studies (TWTOS).

A mixed methods design that combined quantitative and qualitative approaches was used. Five research questions were formulated to guide the collection and analysis of the data. Two instruments, the Global Knowledge and the Global Mindedness scales were used for all 90 secondary teachers. The global knowledge instrument was developed to measure college students' knowledge and beliefs in global understanding (ETS, 1981). Teachers in this study were scored on each correct answer on 50 questions. The global mindedness instrument consisted of 30 items. The instrument was developed as a measure of world-mindedness, international understanding, feminist theory, and 
education (Hett, 1993). ANOVA and Chi square techniques were used to measure variances and the relationships among the factors.

Observation and interview techniques were used for the collection of the qualitative data. Seven social studies teachers, two of whom team-taught a class, were selected for these classroom observations and interviews. Through them, the researcher investigated whether teachers from a globally oriented social studies education program applied more global knowledge, global mindedness, and appropriate pedagogy in the classroom than teachers from non-globally-oriented social studies education programs.

\section{Summary of Findings}

In this section, the findings of the study are presented in relation to the five research questions. Findings are discussed in the following section.

\section{Research Question \#1}

Is there a significant difference among teachers in GOSSE, non-GOSSE, and TWTOS groups in their global knowledge and global mindedness? A significant difference was found between groups in global knowledge. Teachers in the GOSSE program group showed a higher level of mastery in their global knowledge than those in non-GOSSE and TWTOS groups. Therefore, the first null hypothesis was not rejected. However, since no significant difference was found in their global mindedness, this part of the null hypothesis was rejected.

\section{Research Question \#2}

Is there a significant difference between GOSSE and non-GOSSE/TWTOS groups in their global knowledge and global mindedness? No significant difference was found between GOSSE and non-GOSSE/TWTOS groups in their global mindedness. 
Therefore, the second null hypothesis was rejected. Teachers in the GOSSE group did not show a higher level of mastery in their global knowledge and global mindedness than those in non-GOSSE and TWTOS when the groups were combined.

\section{Research Question \#3}

Is there a significant difference between GOSSE/non-GOSSE and TWTOS groups in their global knowledge and global mindedness? Teachers in GOSSE/ nonGOSSE groups did not show a higher level of mastery in their global knowledge and global mindedness than those in the TWTOS group. Therefore, the third null hypothesis was rejected.

\section{Research Question \#4}

Is there a relationship between age, gender, degree, and years of teaching experience on global knowledge and global mindedness? No interactions were found between age, gender, and years of teaching experience on global knowledge and global mindedness. Therefore, the fourth null hypothesis was rejected.

\section{Research Question \#5}

Do teachers from the GOSSE group teach from a global perspective and infuse global perspectives into the curriculum differently than teachers from the non-GOSSE group? Teachers in both the GOSSE and non-GOSSE groups taught and infused global perspectives into the curriculum. They exhibited no difference in the level of infusion of global perspectives in their lessons. However, there was a major difference in the use of a conceptual framework or model to teach global education. The strategies frequently used by teachers in both groups were: issues-centered, role-playing, group activity, lecture, demonstration, and debate. 


\section{Discussion of Findings}

The following questions form the framework for this section: (a) Does the teacher demonstrate knowledge of global knowledge, global mindedness, and global pedagogy?

(b) Does the teacher allow for the exploration of global concepts and ideas, and discussion of current or controversial issues in the classroom? and (c) Does the teacher allow for the use of multiple perspectives, convergent, and divergent view points in the classroom? The following findings emerged from the data analysis.

First, training in teaching global education contributed to teachers' global knowledge. This finding was affirmed by the fact that teachers from the GOSSE program, on average, scored higher on the global knowledge scale than teachers from the non-GOSSE programs and TWTOS group.

Second, teacher attitudes were not influenced by their participation in any particular global education programs. The implication of this finding is that changes in attitudes require different methods of instruction beyond those currently employed in institutions of higher education programs that are globally-oriented. Furthermore, since attitudes are more deeply embedded in cultural backgrounds and norms than in brief encounters with positive influences (such as those found in semester courses of instruction), sustained reinforcement efforts are required to produce enduring attitudinal change. Such efforts take time and should not only be infused in general teacher training curricula, but should also be continued through in-service workshops, seminars, and conferences for teachers. Although the GOSSE teacher group did have a higher global knowledge score, and lessons conveyed a more coherent theoretical framework, the lack of any difference in global attitudes noted in the survey results was reflected in similar 
global mindedness in classroom instruction. Furthermore, because the non-GOSSE teachers scored higher on the Global Mindedness scale than the GOSSE teachers, one may conclude that the globally oriented program the GOSSE teachers attended failed to meet at least one of its objectives.

Third, teachers who teach other subjects were not significantly different in their global knowledge and global mindedness than teachers from both GOSSE and nonGOSSE programs, when both groups were combined. This suggests that teachers who teach other subjects may have acquired global knowledge and global mindedness from several sources such as the media, magazines, peers, workshops, books, conferences, newspapers, and their own college experiences.

Fourth, no relationship existed between gender, degree, and years of teaching and teachers' global knowledge and global mindedness. This suggests that teachers' age, years of teaching, and gender do not affect teachers' global knowledge and global mindedness. Similarly, years of teaching and advanced degrees earned did not appear to increase these teachers' global knowledge and global mindedness. Finally, the data did not show any significant difference between the levels of global knowledge and global mindedness of male and female secondary teachers.

\section{Global Knowledge}

The findings showed that teachers who were trained in teaching from a global perspective had a higher level of global knowledge than teachers who were not trained in teaching from a global perspective. Findings from recent studies in global awareness and pedagogy conducted locally and nationally are consistent with the findings of this study. In their studies, Benitez (2001), Cruz (1990), Kirkwood (1995), Merryfield (1997), 
Tucker (1983) and (Zong, 1999) have concluded that an effective global education program does make a difference in improving teachers' global knowledge and global pedagogy.

Global Pedagogy

Observations were conducted, lesson plans were examined, and repeated conversations were held with teachers to answer the fifth research question, which focused on global pedagogy. Studies in global pedagogy conducted in Miami-Dade County and elsewhere support the findings of this study (Tucker, 1983; Cruz, 1990; Kirkwood, 1995; Zong (1999). As in the literature, global classroom activities observed in this study included current events, role-playing, simulations, and discussion. Other typical global activities found both in the literature and observed in this study are problem-solving and decision making exercises. These activities provide students the opportunity to develop their cognitive, affective, and participatory skills (Diaz, Massialas, \& Xanthopoulas, 1999).

Diaz et al. (1999) believe that pedagogy for global education allows students experiences in the cognitive, affective, and participatory domains. They argue that in the cognitive domain, information and facts should be presented with concepts and themes. In the affective and participatory domains, learning activities should allow students to understand global events, issues, and problems from the perspectives of others. In participating in activities where they can demonstrate this understanding, students become more sensitive and empathetic. Furthermore, it follows that students should also become more knowledgeable about global events, issues, and problems when they participate in appropriate activities such as those indicated above. In the process students 
come have a deeper understanding of and appreciation for human and cultural differences and commonalities. This appreciation and understanding of other people and their world, is one of the core values of global education.

\section{Conclusion}

Based on the findings of this study, the researcher concluded that the globally oriented social studies program did have an effect on teachers' acquisition of knowledge and the underlying conceptual clarity of their lessons, but did not have a significant effect on attitude change toward global education.

\section{Implication for Practice}

The implication is that changes in attitudes require different methods of instruction beyond those currently employed in preparing pre- and in-service teachers in globally-oriented programs. Furthermore, since attitudes are embedded in cultural backgrounds and norms, more than brief encounters with positive influences, such as those typically found in semester courses of instruction, are required to produce enduring attitudinal change.

\section{Recommendations}

Based on the findings of this study and the conclusion reached, the following recommendations are offered:

1. To enhance global knowledge of social studies teachers, all social studies education programs should incorporate the study of current global realities as well as accomplished global instructional practices. This addresses the cognitive domain concerns of social studies teachers. 
2. To address affective domain concerns raised in this study, social studies teacher education programs should all have more of an emphasis on global mindedness. This must be addressed more effectively in order to teach the whole teacher so that the teacher may teach the whole learner.

\section{Future Research}

Research should now focus on gaining greater understanding of those elements that do influence teachers' global mindedness. These elements must be integrated into college curricula so that teacher preparation programs have a better approach to influencing teachers' global attitudes than they now have. Effecting change in secondary school social studies content and methods depends on changing how teachers approach global education. 


\section{REFERENCES}

Alger, C. F., \& Harf, J. E. (1986). Global education: Why? For whom? About what? In R. E. Freeman (Ed.), Promising practices in global education: A handbook with case studies (pp. 1-31). New York: The National Council on Foreign Language and International Studies.

American Forum for Global Education (2002). Annual Report. New York: Author

America in transition: International frontier. (1989). Report of the Task Force on International Education. Washington, DC: National Governors Association.

Anderson, L. F. (1973). Schooling and citizenship in a global age. Evanston, IL: Northwestern University.

Anderson, L. F. (1990). A rationale for global education. In K.A. Tye (Ed.), Global education: From thought to action (pp. 13-34). Alexandria, VA: Association for Supervision and Curriculum Development.

Apple, M. (2002). Patriotism, pedagogy, and freedom: On the educational meaning of September 11. Retrieved, June 19, 2002 from http://www.tcrecord.org/content.asp

Banks, J. A. (1985). Teaching strategies for the social studies: Inquiry, valuing, and decision-making. New York: Longman.

Barber, R. B. (1995). Jihad vs. McWorld. New York: Random House.

Becker, J. M. (1979). The world and the school: A case for world centered education. In J. M. Becker (Ed.), Schooling for a global age (pp.33-56). New York: McGraw-Hill.

Benitez, H. (1994). Globalization of U.S. history: Five strategies. Social Education, 27, 14-17.

Benitez, H. (2001). Does it really matter how we teach? The socializing effects of a globalized U.S. history curriculum. Theory and Research in Social Education. 29, 290-307.

Berg, L. B. (2001). Qualitative research methods for the social sciences. Boston: Allyn \& Bacon.

Bogdan, R. C., \& Biklen, S. K. (1982). Qualitative research for education. Boston: Allyn \& Bacon. 
Borich, D. G. (2003). Observation skills for effective teaching. Upper Saddle River, NJ: Prentice Hall.

Boyer, E. L. (1983). High school: A report on secondary education in America. New York: Harper \& Row.

Bruce, M. G., Podenski, R. S., \& Anderson, C. M. (1991). Developing a global perspective for teacher education. Journal of Teacher Education, 42, 21-27.

Case, R. (1991). Key elements of a global perspective. Social Education, 57, 318-325.

Cogan, J. (1977). Global education in elementary schools: Teacher education. Social Education, 41, 46-49.

Cruz, B. (1990). The effect of a social studies teacher training program emphasizing global education on the teaching behaviors of secondary level pre-service teachers. Unpublished doctoral dissertation, Florida International University, Miami, FL.

Demovsky, S., \& Niemuth, J. (2000). The global classroom: A study in appreciation, awareness, and acceptance of different cultures and people in our ever changing world. Master's Action Research Project, Saint Xavier University, Chicago, IL.

Diaz, C., Massialas, B. G., \& Xanthopoulos, G. (1999). Global perspectives for educators. Boston: Allyn \& Bacon.

Educational Testing Service. (1981). Global Knowledge Scale. Princeton, NJ: Educational Testing Service.

Florida Department of Education (1981). State plan for global education in Florida. Tallahassee, FL: Department of Education

Florida Curriculum Framework. (1996). Social studies: PreK-12 sunshine state standards and instructional practices. Tallahassee, FL: Department of Education.

Foster, D. (2002). The global etiquette guide to Africa and the Middle East. New York: John Wiley \& Sons.

Friedman, L. T. (1999). The lexus and the olive tree: Understanding globalization. New York: Farrar, Straus \& Giroux.

Gall, M. D., Gall, J. P., \& Borg, W. R.(1996). Educational research: An introduction (6 ${ }^{\text {th }}$ ed.). White Plains, NY: Longman. 
Gaudelli, B. (1999, November). Teacher as self: Understanding pedagogy in global education. Paper presented at the annual meeting of the College and University Faculty Association National Council for the Social Studies, Washington, DC.

Gabler, I. C., \& Schroeder, M. (2003). Constructivist methods for the secondary classroom: Engaged minds. New York: Allyn \& Bacon.

Global Awareness Program. (n.d.). Global awareness training program. Miami, FL: College of Education, Florida International University.

Gilliom, M. (1993). Mobilizing teacher educators to support global education in preservice programs. Theory into Practice, 32, 40-46.

Giroux, H. (2002, June 9). Democracy, freedom, and justice after September $11^{\text {th }}$ :

Rethinking the role of educators and the politics of schooling. Retrieved June 19, 2002, from http://www.tcrecord.org/content.asp

Grossman, D. L. (1990). The making of a teacher: Teacher knowledge and teacher education. New York: Teachers College.

Grossman, D. L. (1998). Setting a context for global education. Social Studies Review. 37, 6-8.

Green, S. B., Salkind, N., \& Akey, T. (2002). Using SPSS for window's: Analyzing and understanding data. Saddle Upper River, NJ: Prentice Hall.

Hanvey, R. (1976). An attainable global perspective. New York: Center for Global Perspectives.

Hayhoe, R., \& Pan, J. (2001). Knowledge across cultures: A contribution to dialogue among civilizations. Comparative Education Research Center, Hong Kong: University of Hong Kong

Hett, J. E. (1993). The development of an instrument to measure global-mindedness. Unpublished doctoral dissertation. University of San Diego, San Diego: CA.

Hinkle, D. E., Wiersma, W., \& Jurs, S. G. (1998). Applied Statistics for the behavioral sciences. New York: Houghton Mifflin.

Howell, D. C. (1997). Statistical methods for psychology. Boston: Wadsworth.

Jackson, R .J. (2003). Annual edition: Global issues. Boston: McGraw-Hill.

Kniep, W. M. (1986). Defining global education by its contents. Social Education, 50, 437-466. 
Kniep, W. M. (1989). Social studies within global education. Social Education, 53, 399403.

Kirkwood, T. F. (1995). Teaching from a global perspective: A case study of three high school social studies teachers. Unpublished doctoral dissertation, Florida International University, Miami, FL.

Kirkwood, T. F. (2001, January/February). Our global age requires global education: Clarifying definitional ambiguities. The Social Studies, 92, 10-15.

Lamy, S. L. (1991). Global education: A conflict of images. In K.A. Tye (Ed.), Global education: From thought to action (pp.49-63). Alexandria, VA: The Association for Supervision and Curriculum Development.

Marquis, C., \& Yirchott, T. (1998). Developing a global perspective in your classroom. Social Studies Review, 37, 38-40.

Massialas, B. G. (1991). Education for international understanding. In J. P. Shaver (Ed.), Handbook of research on social studies teaching and learning. A project of the National Council for the Social Studies (pp. 448-456). New York: MacMillan.

Merryfield, M. (1991). Preparing American secondary social studies teachers to teach from a global perspective: Journal of Teacher Education, 42, 11-20.

Merryfield, M. (1992). Preparing social studies teachers for the twenty-first century: Perspectives on effectiveness from a study of six exemplary teacher education programs in global education. Theory and Research in Social Education $20,17-46$.

Merryfield, M. (1995). Institutionalizing cross-cultural experiences and international expertise in teacher education: The development and potential of a global education PDS network. Journal of Teacher Education, 46, 19-29.

Merryfield, M. (2001). Moving the center of global education: From imperial world views that divide the world to double consciousness, contrapuntal pedagogy, hybridist, and cross-cultural competence. In B.W. Stanley (Ed.), Critical issues in social studies for the $21^{\text {st }}$ century (pp. 179-208). Greenwich, CT: Information Age Publishing.

Merryfield, M., \& Kasai, M. (2004). How are teachers responding to globalization? Research and Practice Social Education. 68, 354-359. 
Merryfield, M., Jarchow, E., \& Pickets, S. (1997). Preparing teachers to teach global perspective: A handbook for teacher educators. Thousand Oaks, CA: Corwin Press.

Merryfield, M., \& White, C. S. (1996). Issues centered global education. In R. Evans \& D.W Sax (Eds.), Handbook on teaching social studies: NCSS bulletin 93 (pp.177187). Washington, DC: National Council for the Social Studies.

Miami-Dade County Public Schools. (2003). District and school profiles. Office of Educational Planning and Quality Enhancement: Miami, FL.

Michigan Department of Education. (n.d.). Guidelines for global education. Lansing, MI: Michigan Department of Education.

Morgan, G. A., \& Griego, O. A. (1998). Easy use and interpretation of SPSS for windows: Answering research questions with statistics. Mahwah, NJ: Erlbaum.

Morrison, G. R., Ross, M. S., \& Kemp, E. J. (2004). Designing effective instruction. New York: John Wiley \& Sons.

National Council for the Social Studies. (1994). Expectations of excellence: Curriculum standards for social studies. Bulletin 89. Washington, DC: Author.

National Commission on Social Studies in the Schools. (1989). A nation at risk: The imperative for educational reform. Washington, DC: U.S. Government Printing Office.

National Commission on Excellence in Education. (1983). Global education. position statement prepared by International Activities Committee. Washington, D.C.

Shulman, L. S. (1987). Those who understand: Knowledge growth in teaching. Educational Research, 15, 4-14.

SPSS (2003). SPSS for Windows 11.1 [computer software]. Chicago: SPSS Inc.

Steven, J. (1999). Intermediate statistics: A modern approach. Mahwah, NJ: Erlbaum.

Stromquist, N. P., \& Monkman. L. (2000). Globalization and education: Integration and contestation across cultures. New York: Rowman \& Littlefield.

Sunal, C. S., \& Haas, M. E. (2002). Social studies for elementary and middle grade: A constructivist approach. Boston: Allyn \& Bacon. 
Taylor, H. E. (1995). Teacher research and reflective narrative analysis: Methods of learning about and from implementing global education. Unpublished doctoral dissertation, Ohio State University, Ohio.

Titus, C. (1994). Civic education for global understanding. ERIC Digest. (ERIC Document Reproduction Service No. ED 370 882)

Torney-Purta, J. (1985). Predictors of global awareness and concern among secondary school students. Columbus, $\mathrm{OH}$ : The Mershon Center.

Tucker, J. L. (1982). Developing a global dimension in teacher education: The Florida International University experience. Theory into Practice, 21, 212-217.

Tucker, J. L. (1983). Teacher attitudes toward global education: A report from Dade County. Educational Research Quarterly, 8, 165-177.

Tucker, J. L. (1988). Social studies for the $21^{\text {st }}$ century. Social Education, 52, 209-214.

Tucker, J. L. (1990). Global change and American citizenship education: The vital role of history. Social Education, 54, 312-315.

Tucker, J. L. (1991). Global education is essential to secondary school social studies. Bulletin, NASSE 75, 43-51.

Tucker, J. L. (1993). Global perspectives for teachers: An urgent priority. Journal of Teacher Education, 42, 3-10.

Tucker, J. L. (1996). NCSS and international/global education. In O.L. Davis (Ed), NCSS in retrospect, 5, 45-53. Washington, DC: National Council for the Social Studies.

Tucker, J. L., \& Cistone, P. J. (1991). Global perspectives for teachers: An urgent priority. Journal of Teacher Education, 42, 3-10.

Tucker, J. L., \& Evans, A. M (1996). Crucial Issues in Teaching Social Studies K-12. In B. G. Massialas \& R. F. Allen (Eds.), Critical issues in teaching social studies K-12 (pp. 181-209). Belmont, CA: Wadsworth Publishing.

Tye. K. A. (1991). Global education: From thought to action. Alexandria, VA: The Association for Supervision and Curriculum Development.

U.S. Commissioner of Education's Task Force on Global Education. (1979). Report with recommendations. Washington, D.C. 
Wilson, A. (2001). Growing toward teaching from a global perspective: An analysis of secondary social studies pre-service teachers. International Social Studies Forum, $1,127-143$.

Wright, A. (1994). Implementation of global education in the classroom: A comparison of Swedish and American education. In J. Easterly (Ed.), Promoting global teacher education. Reston, VA: ATE.

Wright, A. (1996). Teachers' and students' perception of global challenges: Are they the same? International trends and developments in social studies: Seminar Report on the International Assembly of the NCSS, Washington, D.C.

Zong, G. (1999). The effects of participation in an internet-based project on the development of global knowledge, global mindedness, and global pedagogy among pre-service social studies teachers. Unpublished doctoral dissertation, Florida International University, Miami, FL. 
APPENDICES 
Appendix A: Permission to Use Global Knowledge Scale Reprinted by permission of Educational Testing Service, 1981 
Oetober 22, 2002

\section{Sadiq A. Abdullahi}

Graduate Teaching Assistant

Florida International University

College of Education

University Park Campus, ZEB 314

Miami, FL 33199

Dear Mr. Abdullahi:

Thank you for your letter in which you requested permission to use the "Global Understanding" Research Instrument as part of your dissertation research study entitled "Teachers' Knowledge, Awareness and Pedagogy of Global Education in Secondary Schools" at Florida International University.

Educational Testing Service is pleased to grant royalty-free, noncxclusive, nontransferable permission to reproduce the instrument listed on the attached appendix. The following tems apply to this permission:

1. The material is to be used only for the research purposes deseribed in your letter and is not to be distributed, published, or used in any other manner without written permission from ETS.

2. Please use the following credit line following the source citation on the page where you use the material and/or other appropriate location:

Reprinted by permission of Educational Testing Service, the copyright owner.

3. The materials must be placed in an appendix to the dissertation, and the appendix must not be made available to University Microfilms, Inc.

4. You will assume responsibility for the analyses and conclusions of your study and, other than acknowledgment of the source of the questions, you will not use ETS' name in such a way as to imply participation in or responsibility for your research.

5. Please send a copy of your research results (and/or dissertation) to the undersigned when available.

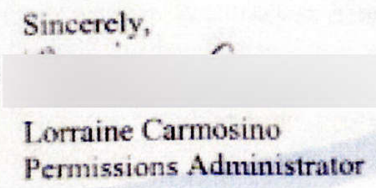

Rospdde Roed * Princeton, NJ 08541 - Thi E09.921.9000 - Fax: 809.734.5183 - Wob: www.sts.crg 
Appendix B: Teacher Consent Form 


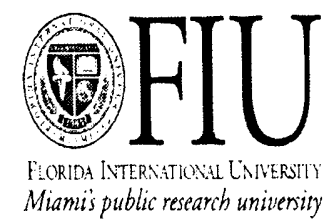

\section{CONSENT TO PARTICIPATE IN A RESEARCH STUDY}

I freely and voluntarily consent to be a participant in the research project listed above to be conducted at my school site with Sadiq A. Abdullahi, who is the principal investigator. I am told that my participation will require 2 hours total of my time. I will be participating in this study with approximately 150 other teachers.

I understand that the purpose of this research is to identify (a) what global knowledge social studies teachers have, (b) what instructional techniques they know and use for teaching about global education and (c) what dispositions and awareness they have of global mindedness. I understand that the procedures will be as follows: (1) I will be asked to complete a 15 minute questionnaire for each of the categories listed below about my global knowledge and the instructional techniques I use to teach about global education; (2) the researcher will instruct me in how to use the instruments, which cover three categories: Subject Matter Knowledge, Instructional Strategies and Disposition; (3) I will be asked to complete a 15 minute questionnaire at the end of my observation.

I understand that the risks involved as a participant in this project is minimal. I understand that my participation will assist with the researcher gathering knowledge in this area of study. I also understand that one possible benefit would be my acquiring new knowledge and a new way of teaching about the world. Participation in this study is of no cost to me.

I understand that I may withdraw my consent and discontinue participation in this research project at any time with no negative consequences. All information pertaining to this study and participation will be kept in a locked cabinet. I further understand that files will only be identifiable by subject number. This research will be presented in group format, no names will be disclosed. My responses are strictly confidential and would only be disclosed as required by law.

I have been given the right to ask questions concerning the procedure, and any questions have been answered to my satisfaction. 1 understand that if any new findings are developed during the time that I am in this study that may affect my willingness to continue to be in the study, I will be informed as soon as possible.

I understand that if I desire further information about this research, 1 should contact Dr. Mohammed Farouk at 305-348-3199. I also understand that if I have any questions concerning the rights of human subjects or injury that I feel 1 have incurred related to this study, I may contact Dr. Bernard Gerstman, the Chairperson of the Institutional Review Board at Florida International University at 305-348-3115 or 305-348-2494.

I have read and I understand the consent form.

Signature of Participant

Printed Name

Date 
I have explained and defined in detail the research procedure in which the participant has agreed to participate and have offered him a copy of this informed consent form. 
Appendix C: Global Education Checklist 


\section{CLASSROOM}

Directions: Below are a number of global instructional teaching skills. Please check Yes or No to indicate whether you use these skills or not in the classroom.

\begin{tabular}{|l|l|l|}
\hline 1. Do you use advance organizer in the classroom? & & \\
\hline 2. Do you use cooperative learning strategies? & & \\
\hline 3. Do you use concept attainment or mapping strategies? & & \\
\hline 4. Do you use the inquiry method in the classroom? & & \\
\hline 5. Do you use role - playing strategies in the classroom? & & \\
\hline 6. Do you use the inductive method in the classroom? & & \\
\hline 7. Do you use the deductive method in the classroom? & & \\
\hline $\begin{array}{l}\text { 8. Do you use the constructivist method of teaching in } \\
\text { the classroom? }\end{array}$ & & \\
\hline $\begin{array}{l}\text { 9. Do you use various teaching strategies to teach about } \\
\text { the world? }\end{array}$ & & \\
\hline $\begin{array}{l}\text { 10. Do you infuse global perspective in your lessons? } \\
\text { culture? }\end{array}$ & & \\
\hline
\end{tabular}

\section{Permission Granted}

Global Awareness Program

Directions: Below are a number of classroom activities. Please check Yes or No to indicate the infusion of global teaching in your classroom.

\begin{tabular}{|l|l|l|}
\hline $\begin{array}{l}\text { 1. Do you point out on a map or globe cities and } \\
\text { countries that come up in the course of discussion? }\end{array}$ & & \\
\hline $\begin{array}{l}\text { 2. Do you include materials that mention other countries } \\
\text { in addition to the U.S.? }\end{array}$ & & \\
\hline $\begin{array}{l}\text { 3. Do you stress the need to know about the rest of the } \\
\text { world? }\end{array}$ & & \\
\hline $\begin{array}{l}\text { 4. Do you out point that people can have different ways } \\
\text { of doing the same thing and that's okay? }\end{array}$ & & \\
\hline $\begin{array}{l}\text { 5. Do you point out international linkages in your local } \\
\text { community? }\end{array}$ & & \\
\hline $\begin{array}{l}\text { 6. Do you mention that individual decisions can have an } \\
\text { effect on our environment and the world in which we } \\
\text { live? }\end{array}$ & & \\
\hline $\begin{array}{l}\text { 7. Do you encourage students to think, dream and plan } \\
\text { for the future they would like to see? }\end{array}$ & & \\
\hline
\end{tabular}




\begin{tabular}{|l|l|l|}
\hline $\begin{array}{l}\text { 8. Do you point out similarities among the world's } \\
\text { cultures when teaching about other countries? }\end{array}$ & \\
\hline $\begin{array}{l}\text { 9. Do you point out differences among cultures in a non- } \\
\text { judgmental way when teaching about other } \\
\text { countries/cultures? }\end{array}$ & & \\
\hline $\begin{array}{l}\text { 10. Do you have community people speak to your } \\
\text { students about another country or culture? }\end{array}$ & & \\
\hline $\begin{array}{l}\text { 11. Do you have people speak to your students about a } \\
\text { world issue (e.g. poverty, population, disease, food, } \\
\text { pollution etc.)? }\end{array}$ & & \\
\hline $\begin{array}{l}\text { 12. Do you emphasize that conditions in our world are } \\
\text { constantly changing and we must prepare ourselves to } \\
\text { live in a world conflict and change? }\end{array}$ & & \\
\hline 13. Do you discuss world events in class? & \\
\hline $\begin{array}{l}\text { 14. Do you clearly explain and promote to U.S. while } \\
\text { teaching about other cultures? }\end{array}$ & & \\
\hline $\begin{array}{l}\text { 15. Do you use the issues-centered approach when } \\
\text { infusing global education your classroom? }\end{array}$ & & \\
\hline
\end{tabular}


Appendix D: Global Instruction in the Classroom and Instructional Strategies 
Global Instruction in the Classroom $(\mathrm{N}=60)$

\begin{tabular}{|c|c|c|c|}
\hline $\begin{array}{c}\text { Global Instructional } \\
\text { Questions }\end{array}$ & $\begin{array}{c}\text { GOSSE } \\
(\mathrm{N}=30) \\
\%\end{array}$ & $\begin{array}{c}\text { Non- } \\
\text { GOSSE } \\
(\mathrm{N}=30) \\
\%\end{array}$ & $\begin{array}{l}\text { Hanvey Global Education } \\
\text { Framework }\end{array}$ \\
\hline $\begin{array}{l}\text { 1. Do you point out on the } \\
\text { map or globe cities and } \\
\text { countries that come up in } \\
\text { the course of discussion? }\end{array}$ & & & State of the planet awareness \\
\hline $\begin{array}{l}\text { 2. Do you stress the need to } \\
\text { know about the rest of the } \\
\text { world? }\end{array}$ & & & $\begin{array}{l}\text { Perspective Consciousness; } \\
\text { Knowledge of Global Dynamics; } \\
\text { Cross-Cultural Awareness }\end{array}$ \\
\hline $\begin{array}{l}\text { 3. Do you point out that } \\
\text { people can have different } \\
\text { ways of doing the same } \\
\text { thing and that's okay? }\end{array}$ & & & $\begin{array}{l}\text { Perspective Consciousness; } \\
\text { Knowledge of Global Dynamics; } \\
\text { Cross-Cultural Awareness }\end{array}$ \\
\hline $\begin{array}{l}\text { 4. Do you stress the need to } \\
\text { know about the rest of the } \\
\text { world? }\end{array}$ & & & $\begin{array}{l}\text { Perspective Consciousness; } \\
\text { Knowledge of Global Dynamics; } \\
\text { Cross-Cultural Awareness }\end{array}$ \\
\hline $\begin{array}{l}\text { 5. Do you point out } \\
\text { international linkages in } \\
\text { your local community }\end{array}$ & & & Knowledge of Global Dynamics \\
\hline $\begin{array}{l}\text { 6. Do you mention that } \\
\text { individual decisions can } \\
\text { have an effect on our } \\
\text { environment and the world } \\
\text { in which we live? }\end{array}$ & & & $\begin{array}{l}\text { Perspective Consciousness; } \\
\text { Knowledge of Global Dynamics; } \\
\text { Awareness of Choices }\end{array}$ \\
\hline $\begin{array}{l}\text { 7. Do you encourage } \\
\text { students to think, dream and } \\
\text { plan for the future the future } \\
\text { they would like to see? }\end{array}$ & & & Knowledge of Global Dynamics \\
\hline $\begin{array}{l}\text { 8. Do you point out } \\
\text { similarities among the } \\
\text { world's cultures when } \\
\text { teaching about other } \\
\text { countries? }\end{array}$ & & & $\begin{array}{l}\text { Perspective Consciousness; } \\
\text { Cross-Cultural Awareness }\end{array}$ \\
\hline $\begin{array}{l}\text { 9. Do you point out } \\
\text { differences among cultures } \\
\text { in non-judgmental way } \\
\text { when teaching about other } \\
\text { countries/cultures? }\end{array}$ & & & $\begin{array}{l}\text { Perspective Consciousness; } \\
\text { Knowledge of Global Dynamics; } \\
\text { Cross-Cultural Awareness }\end{array}$ \\
\hline
\end{tabular}




\begin{tabular}{|l|l|l|}
\hline $\begin{array}{l}\text { 10. Do you have } \\
\text { community people speak to } \\
\text { your students about another } \\
\text { country or culture? }\end{array}$ & & Cross-Cultural Awareness \\
\hline $\begin{array}{l}11 \text { Do you have people } \\
\text { speak to your students about } \\
\text { a world issue (e.g. poverty, } \\
\text { population, disease, food, } \\
\text { pollution etc.)? }\end{array}$ & & $\begin{array}{l}\text { Knowledge of Global Dynamics; } \\
\text { Cross-Cultural Awareness; } \\
\text { Awareness of Human Choices }\end{array}$ \\
\hline $\begin{array}{l}\text { 12. Do you emphasize that } \\
\text { conditions in our world are } \\
\text { constantly changing and we } \\
\text { must prepare ourselves to } \\
\text { live in a world of conflict } \\
\text { and change? }\end{array}$ & & $\begin{array}{l}\text { Perspective Consciousness; } \\
\text { Knowledge of Global Dynamics; } \\
\text { Cross-Cultural Awareness }\end{array}$ \\
\hline $\begin{array}{l}\text { 13. Do you discuss world } \\
\text { events in class? }\end{array}$ & & $\begin{array}{l}\text { Perspective Consciousness; } \\
\text { Knowledge of Global Dynamics; } \\
\text { Cross-Cultural Awareness; } \\
\text { State-of-the-Planet Awareness; } \\
\text { Awareness of Human Choices }\end{array}$ \\
\hline $\begin{array}{l}\text { 14. Do you clearly explain } \\
\text { the role of U.S. government } \\
\text { in global politics while } \\
\text { teaching about other } \\
\text { countries/cultures? }\end{array}$ & & $\begin{array}{l}\text { Perspective Consciousness; } \\
\text { Knowledge of Global Dynamics; } \\
\text { Cross-Cultural Awareness }\end{array}$ \\
\hline $\begin{array}{l}\text { 15. Do you use the issues- } \\
\text { centered approach when } \\
\text { infusing global education in } \\
\text { your classroom? }\end{array}$ & & \\
\hline
\end{tabular}


Profile of Social Studies Teachers selected for Classroom Observation

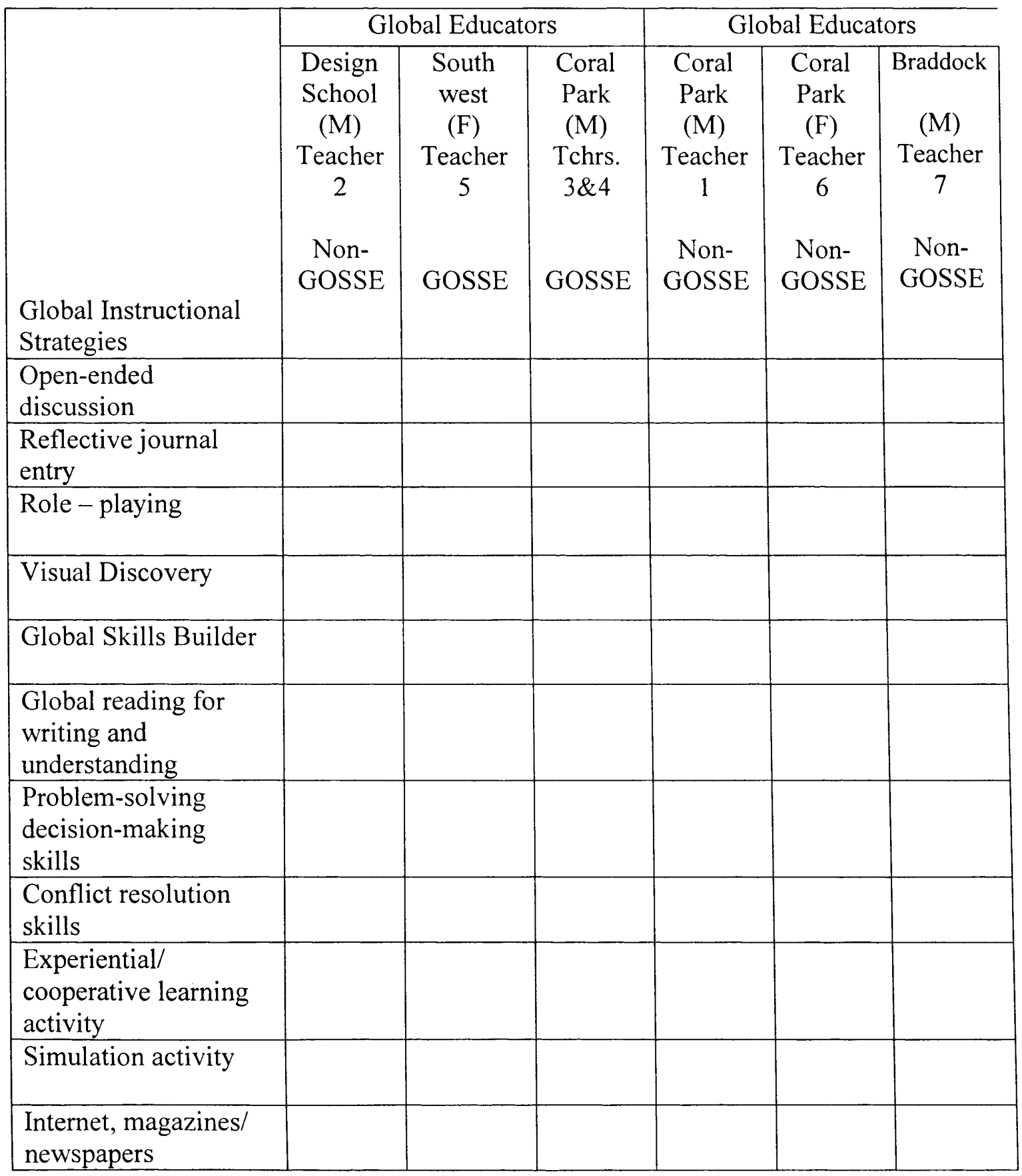


Appendix E: Record of Classroom Observations 
Schedule of Teacher Observation

\begin{tabular}{|c|c|c|c|}
\hline $\begin{array}{c}\text { Date of Classroom } \\
\text { Observations }\end{array}$ & \# of Observations & $\begin{array}{l}\text { \# of Hours of } \\
\text { Observations }\end{array}$ & $\begin{array}{c}\text { Time of } \\
\text { Observation }\end{array}$ \\
\hline $\begin{array}{r}\text { Teacher } 1 \\
5 / 02 / 03 \\
15 / 02 / 03 \\
21 / 02 / 03 \\
26 / 02 / 03\end{array}$ & $\begin{array}{l}1 \\
1 \\
1 \\
1\end{array}$ & $\begin{array}{l}2 \\
2 \\
2 \\
2\end{array}$ & $\begin{array}{l}12: 00-2: 30 \mathrm{pm} \\
12: 00-2: 30 \mathrm{pm} \\
12: 00-2: 30 \mathrm{pm} \\
12: 00-2: 30 \mathrm{pm}\end{array}$ \\
\hline $\begin{array}{r}\text { Teacher } 2 \\
5 / 02 / 03 \\
19 / 02 / 03 \\
21 / 02 / 03 \\
26 / 02 / 03\end{array}$ & $\begin{array}{l}1 \\
1 \\
1 \\
1\end{array}$ & $\begin{array}{l}2 \\
2 \\
2 \\
2\end{array}$ & $\begin{array}{l}\text { 7:30-9:30am } \\
\text { 7:30-9:30am } \\
\text { 7:30-9:30am } \\
\text { 7:30-9:30am }\end{array}$ \\
\hline $\begin{array}{r}\text { Teacher } 3 \& 4 \\
5 / 02 / 03 \\
15 / 02 / 03 \\
21 / 02 / 03 \\
26 / 02 / 03\end{array}$ & $\begin{array}{l}1 \\
1 \\
1 \\
1\end{array}$ & $\begin{array}{l}2 \\
2 \\
2 \\
2\end{array}$ & $\begin{array}{l}9: 30-12: 30 \mathrm{am} \\
9: 30-12: 30 \mathrm{am} \\
9: 30-12: 30 \mathrm{am} \\
9: 30-12: 30 \mathrm{am}\end{array}$ \\
\hline $\begin{array}{r}\text { Teacher } 5 \\
5 / 02 / 03 \\
15 / 02 / 03 \\
21 / 02 / 03 \\
26 / 02 / 03\end{array}$ & $\begin{array}{l}1 \\
1 \\
1 \\
1\end{array}$ & $\begin{array}{l}2 \\
2 \\
2 \\
2\end{array}$ & $\begin{array}{l}9: 30 \mathrm{am}-12: 30 \mathrm{pm} \\
\text { 9:30am-12:30pm } \\
9: 30 \mathrm{am}-12: 30 \mathrm{pm} \\
\text { 9:30am-12:30pm }\end{array}$ \\
\hline $\begin{array}{l}\text { Teacher } 6 \\
5 / 02 / 03 \\
15 / 02 / 03 \\
21 / 02 / 03 \\
26 / 02 / 03\end{array}$ & $\begin{array}{l}1 \\
1 \\
1 \\
1\end{array}$ & $\begin{array}{l}2 \\
2 \\
2 \\
2\end{array}$ & $\begin{array}{l}9: 30 \mathrm{am}-12: 30 \mathrm{pm} \\
9: 30 \mathrm{am}-12: 30 \mathrm{pm} \\
9: 30 \mathrm{am}-12: 30 \mathrm{pm} \\
9: 30 \mathrm{am}-12: 30 \mathrm{pm}\end{array}$ \\
\hline $\begin{array}{r}\text { Teacher } 7 \\
5 / 02 / 03 \\
15 / 02 / 03 \\
21 / 02 / 03 \\
26 / 02 / 03\end{array}$ & $\begin{array}{l}1 \\
1 \\
1 \\
1\end{array}$ & $\begin{array}{l}2 \\
2 \\
2 \\
2\end{array}$ & $\begin{array}{l}9: 30 \mathrm{am}-12: 30 \mathrm{pm} \\
9: 30 \mathrm{am}-12: 30 \mathrm{pm} \\
9: 30 \mathrm{am}-12: 30 \mathrm{pm} \\
9: 30 \mathrm{am}-12: 30 \mathrm{pm}\end{array}$ \\
\hline
\end{tabular}


February 5, 1960

1978-1979

1989-1993

1994-1996

1996-1999

1999-2001

2001-2003

2003 - Present
Born, Kaduna, Nigeria

Kaduna State Sports Council

Kaduna State, Nigeria

Head Tennis Professional

Doral Resort \& Country Club

Miami, Florida

Teacher

Riviera Middle School

Miami, Florida

Graduate Assistant

Department of Curriculum \&

Instruction

Florida International University

Miami, Florida

Social Studies/Global Teacher

Coral Park Senior High School

Miami, Florida

Graduate Assistant

Department of Curriculum \& Instruction

Florida International University

Miami, Florida

Social Studies/Global Teacher

Homestead Senior High School

Miami, Florida 